\title{
Fetal Behavior assessed by Four-dimensional Sonography
}

\author{
${ }^{1}$ Asim Kurjak, ${ }^{2}$ Panagiotis Antsaklis, ${ }^{3}$ Milan Stanojevic, ${ }^{4}$ Selma Porovic
}

\begin{abstract}
The Kurjak's antenatal neurodevelopmental test (KANET) is currently used by many centers in everyday clinical practice as the investigational tool for normal and high-risk fetuses. It has acceptable sensitivity and specificity, adequate positive and negative predictive vales, inter- and intra-observer realiability, and can be easily learned by US specialists with access to 4D US machines. The aim of the KANET is to be widely applied in clinical practice for the selective screening of fetuses with moderate and high neurological risk; hopefully, the early detection of these fetuses would allow at last the diagnosis of severe cases in utero and also an early intervention that could improved the outcome for these neonates.
\end{abstract}

Keywords: Behavior, Brain damages, KANET test

How to cite this article: Kurjak A, Antsaklis $P$, Stanojevic $M$, Porovic S. Fetal Behavior assessed by Four-dimensional Sonography. Donald School J Ultrasound Obstet Gynecol 2017;11(2):146-168.

Source of support: Nil

Conflict of interest: None

\section{INTRODUCTION}

In utero behavior of the fetus is assessed with the assistance of ultrasound (US) technology, through direct observation in utero of real-time movements and activities of the fetus. ${ }^{1-3}$ The US technology that is now used in everyday clinical practice allows us to study not only the anatomy, but also the movements and behavior of the fetus in real time. It has been shown that fetal behavior has a specific pattern that corresponds to brain maturation of the fetus at each week or trimester. ${ }^{4}$ Both anatomic

\footnotetext{
${ }^{1}$ Professor Emeritus, ${ }^{2}$ Senior Lecturer, ${ }^{3}$ Professor and Head ${ }^{4}$ Specialist

${ }^{1}$ Department of Obstetrics and Gynecology, Medical School University of Zagreb, Zagreb, Croatia

${ }^{2}$ Department of Obstetrics and Gynecology; Department of Fetal Maternal Medicine, Alexandra Maternity Hospital University of Athens, Athens, Greece

${ }^{3}$ Department of Obstetrics and Gynecology, Medical School University of Zagreb, Clinical Hospital Sveti Duh, Zagreb, Croatia

${ }^{4}$ Department of Preventive Pediatric Dentistry, Public Health Center of Sarajevo Canton, Sarajevo, Bosnia and Herzegovina

Corresponding Author: Asim Kurjak, Professor Emeritus Department of Obstetrics and Gynecology, Medical School University of Zagreb, Zagreb, Croatia, e-mail: asim.kurjak@ public.carnet.hr
}

and functional development of the human brain is a complex and long-lasting procedure that goes through strictly structured developmental stages, which start from the second month of gestational age and continue after birth up to adult life. ${ }^{4}$ The cornerstones of human brain development are demonstrated in Table $1 .{ }^{4}$ This process cannot be always predetermined, as it is affected by a variety of genetic and epigenetic factors and can be influenced by incidents that may occur during any time during pregnancy. In cases of prematurity, no matter how intensive neonatal units have progressed to be, we still have not reached a point where the conditions of ex life are similar to in utero ones, making extremely premature neonates more susceptible to neurological problems. ${ }^{5,6}$ The degree to which the brain development will be affected by external factors (genetic factors, external stimuli, pathological conditions, or even environmental changes) is uncertain and cannot be predicted. So, neurological impairment is a great challenge, as its diagnosis in utero is very difficult, and even when we suspect it, we are often unable to detect the degree to which the fetus will be affected. What is more we cannot be certain of the exact time that the damage occurs: antepartum, intrapartum, or postpartum, as the diagnosis is most often done after birth. ${ }^{4}$ The diagnosis of neurological impairment is one of the greatest challenges in obstetrics and the cause

Table 1: Major events in neural development

\begin{tabular}{ll}
\hline Developmental event & Peak time of occurrence \\
\hline $\begin{array}{l}\text { - Primary neurulation (dorsal } \\
\text { induction) }\end{array}$ & $3-4$ weeks antenatally \\
- Prosencephalic cleavage & $5-6$ weeks antenatally \\
(ventral induction) & \\
- Neuronal proliferation & \\
Cerebral & $2-4$ months antenatally \\
Cerebellar & $2-10$ months postnatally \\
- Neuronal migration & \\
Cerebral & $3-5$ months antenatally \\
Cerebellar & $4-10$ months antenatally
\end{tabular}

- Neuronal differentiation

Axon outgrowth

3 months - birth

Dendritic growth and synapse 6 months -1 year postnatally formation

- Synaptic rearrangement Birth - years postnatally

- Myelination Birth - years postnatally 
and effect relationship of neurological disabilities most of the times is uncertain. A method that could assess fetal behavior and, as a result, assess the neurological integrity of the fetus would be one that would provide highly useful information. ${ }^{6,7}$ Kurjak's antenatal neurodevelopmental test with the use of four-dimensional (4D) US assesses fetal behavior in a similar way that a neonate is assessed postnatally, and we now have robust evidence from multicentric studies that it can be used in everyday clinical practice.

\section{The Evolution of Fetal Movements and Fetal Behavior Assessment with US}

The cerebral growth and maturation of a fetus appear to be represented by its behavior in utero, ${ }^{8,9}$ while studies have shown that their movements are very good indicators of neurobehavioral organization and of the future neurological integrity of the fetus. ${ }^{10-17}$ Two-dimensional (2D) US allowed up to a point the complete evaluation of the fetal anatomy and gave the opportunity to view fetal movements. One the pioneering studies about the importance of fetal movements was published more than three decades ago offering the first knowledge in this new field of fetal medicine and, at the same time, the inspiration to study the fetal behavior as a whole in utero. ${ }^{18}$ de Vries et $\mathrm{al}^{19}$ followed and analyzed the qualitative and quantitative aspects of giving more details on the movements and a more methodological way of studying them. ${ }^{20,21}$

Based on the first analysis of fetal movements by 2D ultrasonography, de Vries classified movements into different patterns as follows:

Sideways bending: Started between seventh and eighth gestational weeks, slow and small displacements at one or two poles of the fetus occur, lasting from half a second to two seconds, which usually occur as a single event and disappear through gestation.

Startle: A startle consists of a rapid phase contraction of all limb muscles. It often spreads to the trunk and neck. It occurs frequently in the first trimester from 8 weeks on.

General movements: These movements are complex movements including neck, trunk, and limbs that are applicable if the whole body is moved, but no distinctive patterning or sequencing of the body parts can be recognized. They wax and wane in intensity, force, and speed, and they have a gradual beginning and end. These movements are performed from 8 weeks and on.

Hiccups: These consist of a jerky contraction of the diaphragm. Hiccups appear from 9 weeks and on, often in series, for up to several minutes, and isolated arm and leg movements can be observed.
Breathing-like movements: Fetal breathing-like movements are usually paradoxical in a way that every contraction of the diaphragm (which after birth leads to an inspiration) causes an inward movement of the thorax. The onset of fetal breathing-like is around the 10th week of gestation. Early in pregnancy, they are present continually and are associated with activity in the postural muscles of the neck and limbs.

Isolated arm or leg movement: These movements appear around the 10th week of gestation and they vary in speed and amplitude. They involve extension, flexion, external and internal rotation, or abduction and adduction of an extremity, without movements in other body parts.

Twitches: Twitches are quick extensions or flexions of a limb, or the neck. They are not generalized or repetitive.

Clonic movements: These are repetitive movements of one or more limbs at a rate of about three per second.

Isolated retroflexion of the head: Retroflexions of the head are usually carried out slowly, but they can also be fast and jerky. These movements can be seen around the 10th week of gestation and on.

Isolated rotation of the head: Rotation of the head is carried out at a slow velocity and only exceptionally at a higher speed. The head may turn from a midline position to one side and back.

Isolated anteflexion of the head: Anteflexion of the head is carried out only at a slow velocity. The displacement of the head is small. The duration is about one second.

Jaw movements: The onset of irregular jaw opening is at 11 th week. The opening may be either slow or quick. The duration of opening varies from less than 1 to 5 seconds.

Sucking and swallowing: At 13 weeks, rhythmical sucking movements, often followed by swallowing, occur in bursts indicating that the fetus is drinking amniotic fluid.

Hand-head contact: In this pattern of movement, the hand slowly touches the face, and the fingers frequently extend and flex. These movements appear from 10th week onward and, at first, they usually represent an accidental contact of a hand with the face or mouth.

Subgroups of these movements are:

- Hand-to-head: When hand movement ends at contact of fingers with the parieto-occipitotemporal region of the head

- Hand-to-mouth: When hand movement ends at contact of thumb or finger with the mouth, lips, or the immediate oral region

- Hand-near-mouth: When movement ends with fingers in fluid between nose and shoulders/nipples or between both shoulders. Hands must be below eyes 
and within the area defined by the ears, less than a hand away from the mouth

- Hand-to-face: When movement ends with hand in contact with the face (cheeks, chin, forehead)

- Hand-near-face: When movement ends with finger in fluid in front of the face, but not in mouth region

- Hand-to-eye: When movement ends with hand or palm or fingers in the eye region

- Hand-to-ear: When movement ends at hand contact with the ear.

Stretching: This movement is a complex motor pattern, which is always carried out at a slow speed and consists of the following components: forceful extension of the back, retroflexion of head, and external rotation and elevation of the arms. It retains an identical movement form into adult life.

Yawning: This motor activity is similar to the yawning observed after birth: prolonged wide opening of the jaws followed by quick closure, often with retroflexion of the head and sometimes elevation of the arms. This movement pattern is nonrepetitive and it appears around 11 th week. The anatomical criterion for fetal yawning is retraction of the tongue, whereas yawning in adults is characterized by an extended tongue.

Rotation of the fetus: Rotation of the fetus occurs around the sagittal or transverse axis. A complete change in position around the transverse axis, usually with a backward somersault, is achieved by a complex general movement, including alternating leg movements, which resemble neonatal stepping.

It has been suggested that distinguishing between types of fetal movements and behavior according to each trimester could help to dissever routine normal fetal behavioral patterns from possible pathological patterns. ${ }^{21-24}$ The method that brought a revolution to fetal real-time imaging was 4D ultrasonography, which offered a more objective and accurate way than 2D US. ${ }^{24-27}$ The three-dimensional/4D US has now become routine in clinical practice and fetal assessment offering better pictures than 2D US and allowing observation of fetal movements, even detailed ones, such as fingers and facial movements. ${ }^{28,29}$ Especially where the face is concerned, it represents the most visible part of the human being. All major senses are facilitated in this region and expressed through facial expressions. The long-term study of fetuses with 4D US allowed the production of measurable units that could be finally applied systematically for the assessment of fetal behavior. ${ }^{30}$ One of the greatest advantages of 4D US compared with 2D is the detailed pictures of the fetal face (e.g., smiling, crying, mouthing, and blinking), something that cannot be achieved with 2D US. When comparing assessment of fetal behavior by $2 \mathrm{D}$ and $4 \mathrm{D}$ US, the advantage of $4 \mathrm{D}$ is better depiction of fetal facial expressions in three dimensions, with the possibility to assess them in almost real time with the new sophisticated US machines having fast frame rates.

There are now studies that prove that with the use of $4 \mathrm{D}$, differences in fetal behavior can be indeed identified, and with these findings, eventually abnormal characteristics can be identified. ${ }^{31-33}$ The commencement of fetal movements has been shown by US studies that occur very early in fetal life and much earlier than pregnant women can start feeling them. ${ }^{26}$ Until a mother can start feeling them and until delivery, these movements go through a process through which they become more organized and more detailed, such as in facial expressions. ${ }^{34}$ Studies regarding neonatal neurology have shown that the neonatal behavioral examination can give more information about a possible impairment than a typical neurological examination. That initiated a series of studies that aimed to find the exact structure of the development of fetal behavior for each month or each trimester, in order to first of all to define what is a possible normal behavior and then to identify and diagnose abnormal patterns. ${ }^{1-4,18-23,35}$ About 5 years ago, the Zagreb group developed a methodical system for assessing the integrity of the nervous system of fetuses, by applying $4 \mathrm{D}$ US. ${ }^{36}$ This test was named KANET. Its innovation is that it assesses the fetus in the same way that neonates are assessed neurologically after birth, using similar parameters, with the use of $4 \mathrm{D}$ US. ${ }^{37-39}$ While 2D US is used only for the assessment of fetal startles and general movements, introduction of KANET enabled assessment of not only movements, but also some signs used in postnatal neurological assessment like cranial sutures, head circumference, and finger movements of the hand for the detection of neurological thumb (adducted thumb in the clenched fist).

\section{KANET: The Assessment of Fetal Neurobehavior in the 21st Century}

Timely diagnosis of brain impairment is the main reason why so many studies have been conducted regarding the anatomical and functional integrity of the fetal nervous system as well as the understanding of their reactions. The results that these studies showed, gave the motivation for the development of a structured way of assessing fetal behavior in a similar way that neonatal assessment is done. ${ }^{1}$ The KANET is a new pioneering method of fetal evaluation mainly by $4 \mathrm{D}$ US that shows a relationship between fetal behavior and neurodevelopmental processes in different periods of pregnancy, making it possible to distinguish between normal and abnormal brain development. ${ }^{36}$ It consists of general parameters, such as general movements of the fetus and some parameters that are used postnatally for neonatal 
assessment incorporated by the Amiel-Tison Neurological Assessment at Term (ATNAT) signs. ${ }^{37,40}$ The following parameters are included in the KANET: isolated head anteflexion, overlapping cranial sutures, head circumference, isolated eye blinking, facial alterations, mouth opening (yawning or mouthing), isolated hand and leg movements and thumb position, and gestalt perception of general movements (overall perception of the body and limb movements with their qualitative assessment).

Studies show a continuity of the behavioral pattern that follows a fetus from its in utero life to its postpartum attitude, and it has been observed that all movements, which are present in neonates, are also present in fetal life, with the exception of Moro's reflex, which cannot be demonstrated in fetuses. ${ }^{41}$ The absence of Moro's reflex can be attributed to the differences of the environment in which a fetus develops compared with the postnatal environment, and these differences concern mainly the differences of gravity in the two environments. ${ }^{6}$ The parameters finally decided to be used for the KANET were the result of long-term multicentric studies regarding neurological assessment and the general movement's emergence of the fetuses. ${ }^{40,42}$

The KANET is an integrated test consisting of not only parameters that concern in utero behavior and movements, but also signs which are used postnatally for detection of neurodevelopmental impairment (neurological thumb, overlapping sutures, and small head circumference). ${ }^{43}$ The KANET is a test that has been standardized, and studies show that it is a method with good reproducibility; the learning curve is also very reasonable for physicians and medical staff with good US background. ${ }^{43}$ Regarding the gestational age at which KANET should be performed, it has been decided that the best period is the third trimester of pregnancy, and particularly after 28 weeks. The test is proposed to last about 15 to 20 minutes, and it has been decided that it is best to be performed at periods that the fetus is awake. If this is not achievable because the fetus is going through its sleeping period, the test should be repeated in 30 minutes or the following day, at a minimum period of 14 to 16 hours.

When the test is abnormal or the score is borderline, it is proposed that the test is repeated every 2 weeks until delivery. Very important features are facial movements and eye blinking _ "the face is the mirror of the brain". The overall number of movements must be documented in all cases and compared with normal values as presented in previous studied and reviews ${ }^{40,42}$ (Figs 1 to 6).

Examiners who apply KANET should have proper training and adequate experience in low- and high-risk pregnancies. Interobserver and intraobserver variability has to be documented. The suggestion regarding the ultrasonographic machines used is to have a frame rate of at least 24 volumes/second. The KANET consists of eight parameters (Table 2). The results of KANET are divided into three groups: (1) abnormal, when the score is 0 to $5,(2)$ borderline for a score from 6 to 13 , and finally (3) normal for a score 14 to 20 (Table 3). A 2-year
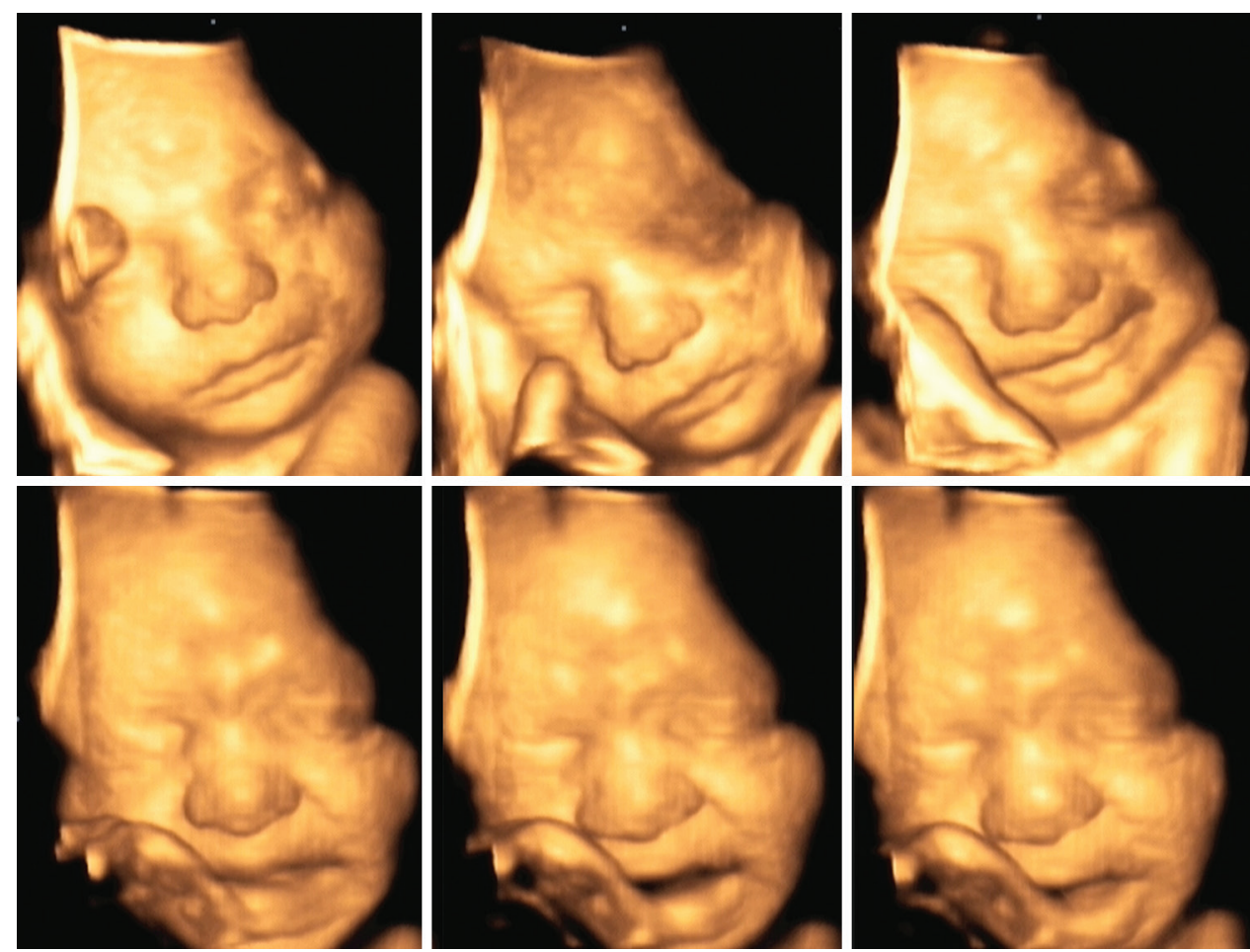

Fig. 1: Typical fetal facial expressions as seen during the performance of KANET and recorded 

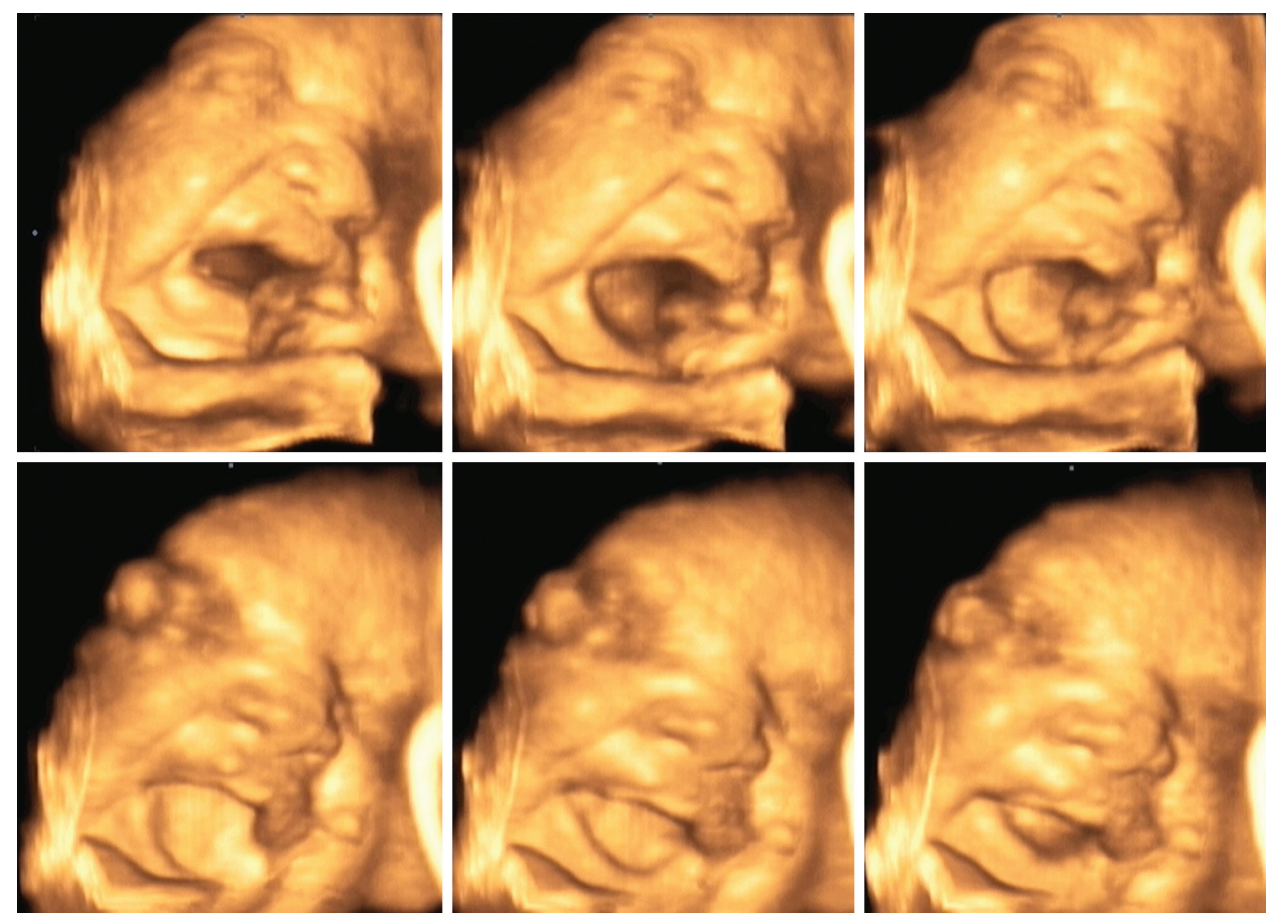

Fig. 2: Mouthing and yawning are important parameters of KANET and a good sign of neurological development
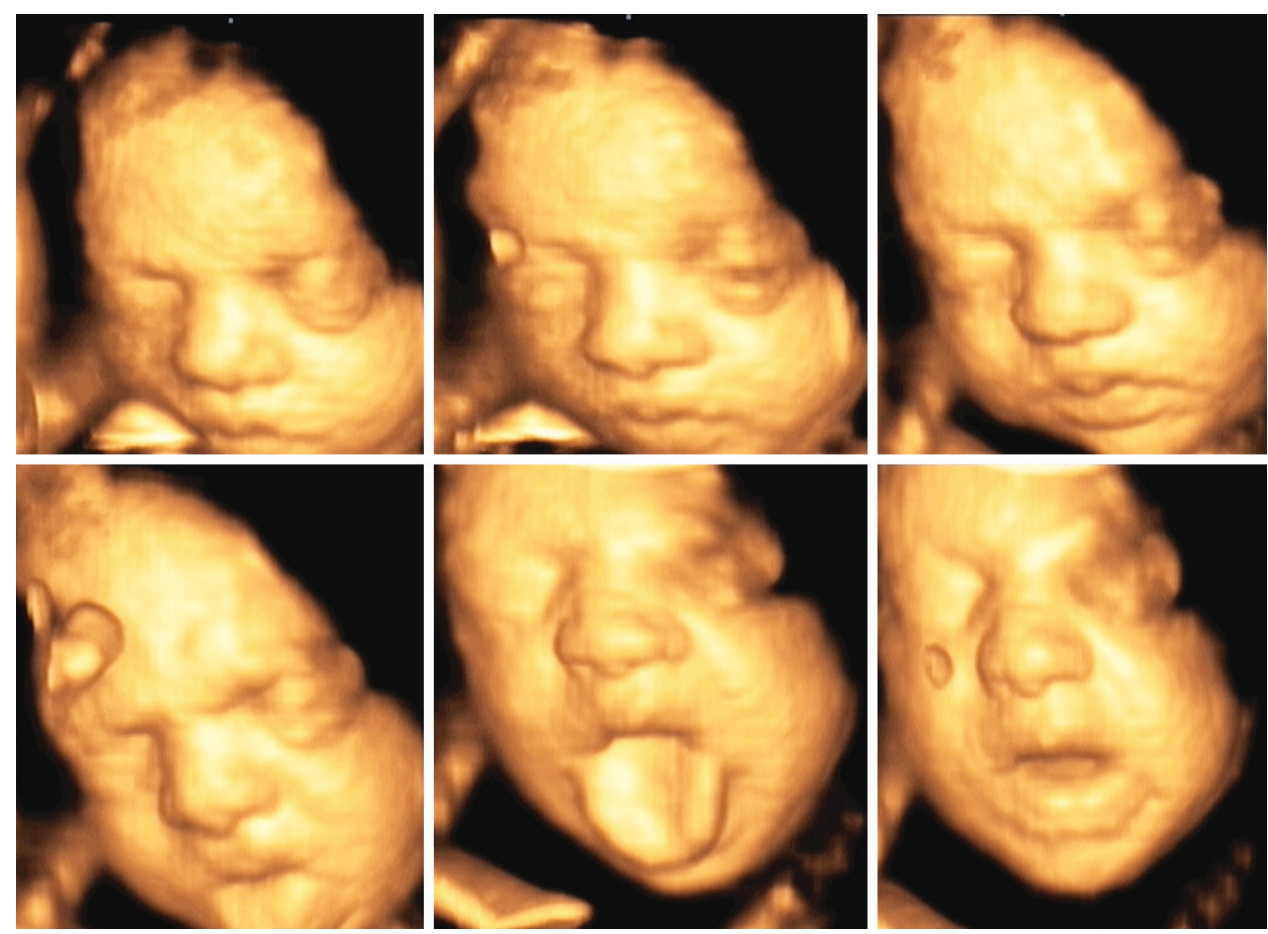

Fig. 3: Typical tongue expulsion while fetus is at a wakeful state

follow-up should be available and documented for all fetuses that KANET has been applied, in order to draw safe conclusions.

The aim of the KANET is to evaluate fetal motoric activity and through that the development of the nervous activity. The KANET depends on realistic images compared with the traditional 2D US and maternal perception of fetal movements, as it can demonstrate fetal movements in real time. As mentioned above, parameters used by KANET are a mixture of general movements, signs adopted by the ATNAT, and these are based on the fact that there is a continuity from fetal life to neonatal life after delivery, plus the fact that the integrity of the fetal nervous system is up to a point represented by the quality and quantity of the movements that a fetus has in utero and its overall behavior. ${ }^{22,44-49}$ 

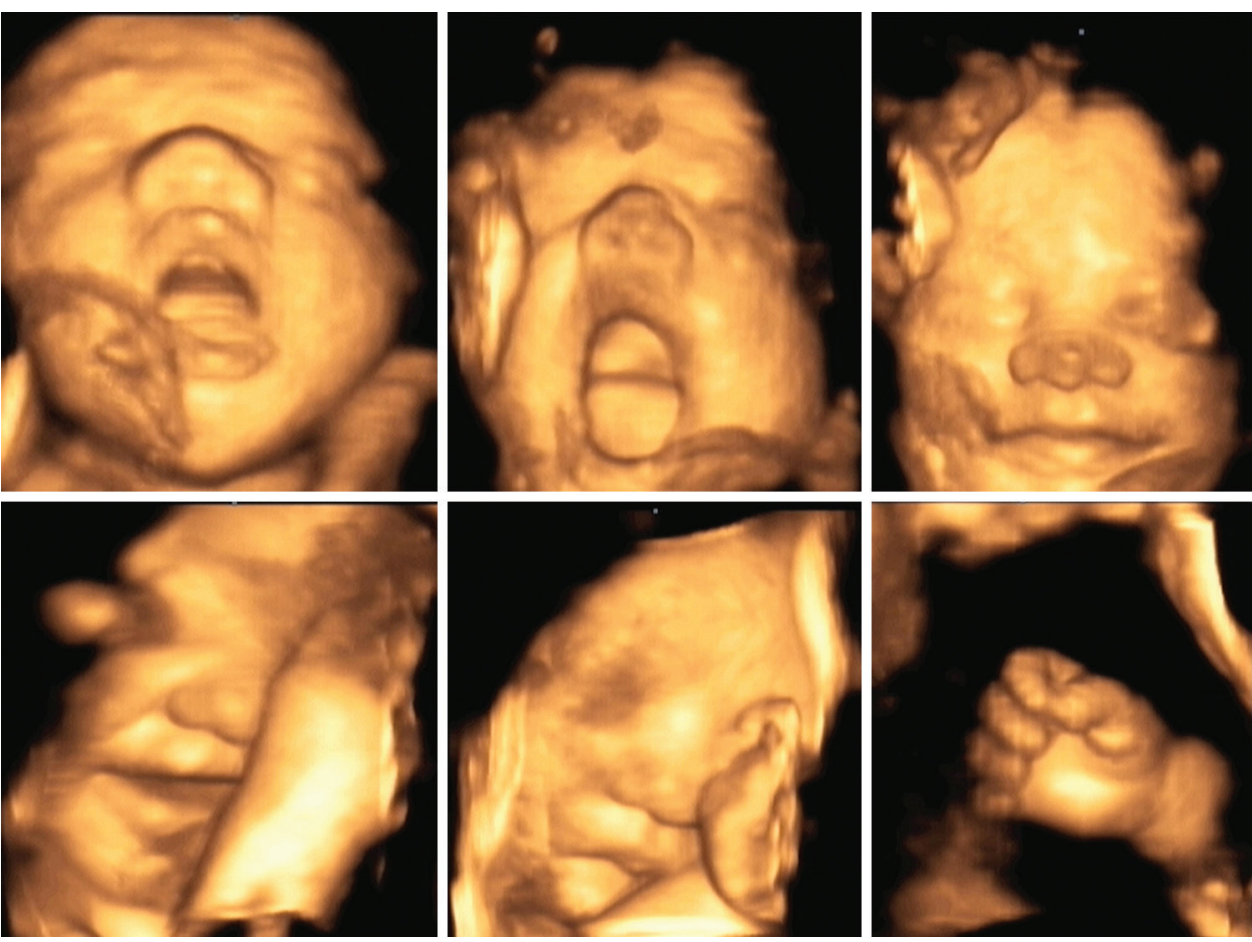

Fig. 4: Mouth opening, yawning, smiling, and finger movements during the performance of KANET
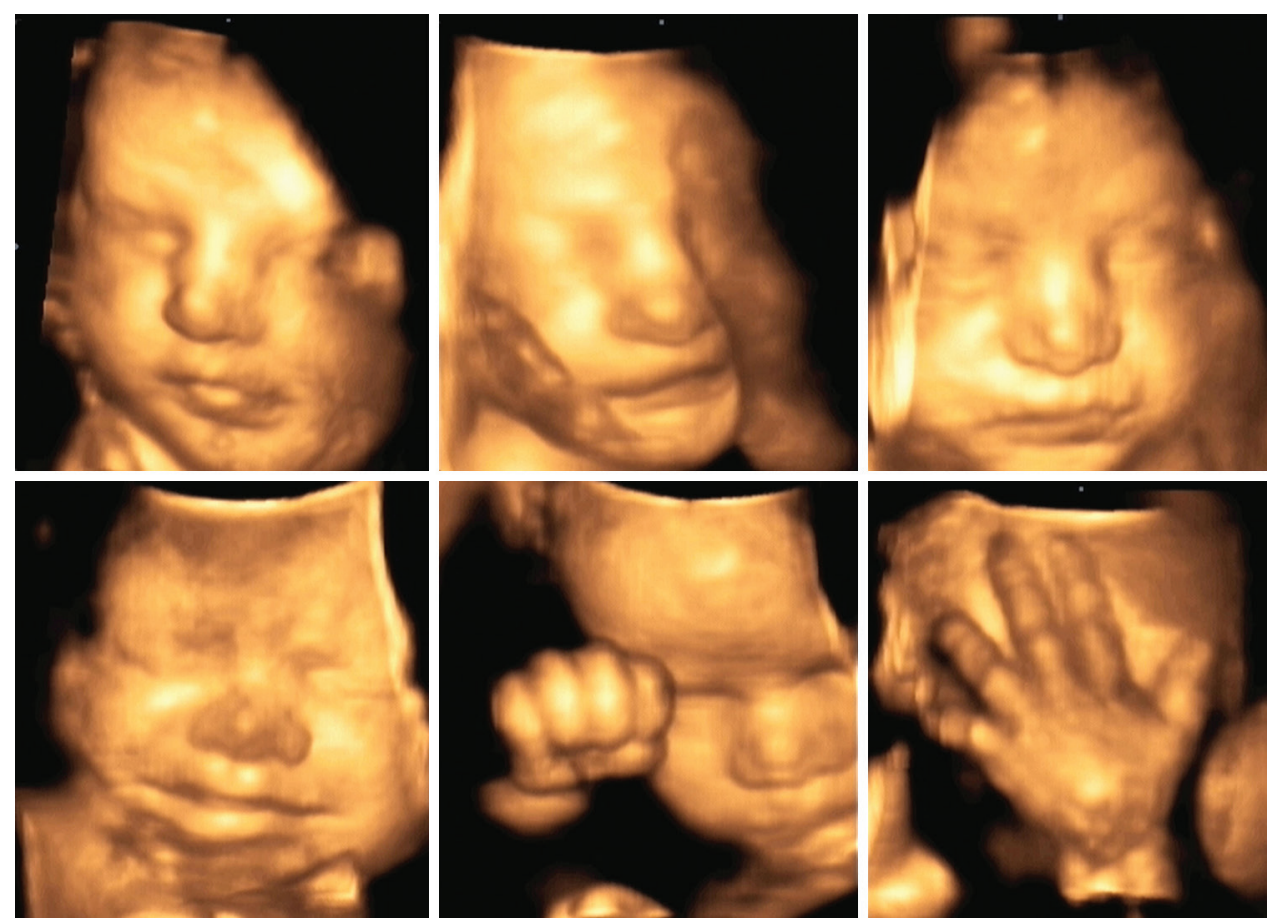

Fig. 5: Facial expressions, eye blinking, and finger movements as part of neurological assessment of the fetus with 4D US (KANET)

Studies ${ }^{50-55}$ show that KANET can identify severe motoric impairment in fetuses with already diagnosed anatomical central nervous system (CNS) abnormalities or chromosomal abnormalities. Also, it has been proven that the results of KANET in both low- and high-risk populations correspond to a very high extent to the final outcome; particularly in high-risk populations, the
KANET can be a very useful tool providing information regarding the prognosis and the grade of impairment of these cases. ${ }^{56}$ The KANET constitutes the first test applying 4D US, which has been standardized, attempting to simplify things, and offers a scoring system with an aim to be introduced in clinical practice. ${ }^{35,57-59}$ Regarding the applicability of KANET, studies show that it is relatively 

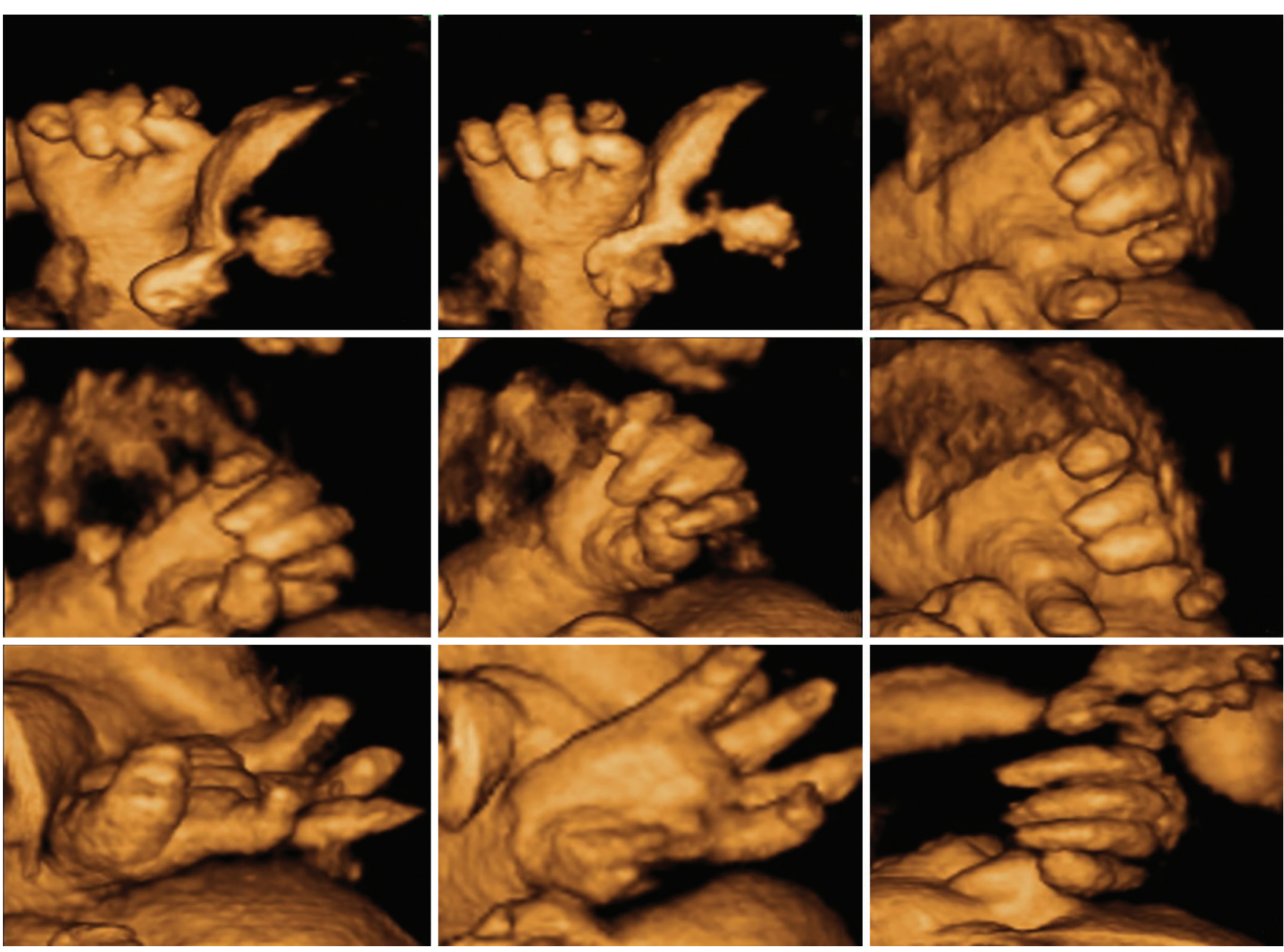

Fig. 6: Fetal hand and finger movements. Detailed movements are very indicative of the neurological maturation and very important parameter of KANET

easy to learn and is well accepted by pregnant women. It has a reasonable learning curve of about 80 cases and the duration of the KANET appears reasonable, as it should last about 15 to 20 minutes. ${ }^{54}$

The KANET is a new test that takes advantage of the potential offered by the evolution of US technology and, especially, 4D US for the better assessment of fetal structural and behavioral integrity and, especially, study details of facial and finger movements. It has been proven that KANET is method that is well accepted by both examiners and pregnant women, and it has been appropriately standardized. The KANET appears to offer useful information about fetal neurobehavior and has the potential to detect and discriminate normal, borderline and abnormal fetal behavior mainly in high-risk pregnancies, so that it can be a valuable diagnostic tool for fetal neurological assessment. ${ }^{43-79}$ So far, the KANET has proven its usefulness in standardization of neurobehavioral assessment, with the potential of prenatal detection of fetuses with severe neuronal dysfunction (Figs 7 to 11). ${ }^{77}$

According to the Bucharest consensus statement on KANET, it is needed to perform 80 KANET tests by experienced US specialist in order to be familiar to assess a fetus with 4D US in 20 minutes. It was calculated that one needs 10 to 15 cases in 7 days to learn the basics of the technique, which can be reproducible. The number of tests was comparable with other US tests like nuchal translucency screening (40 tests by experienced US specialist) and anomaly scan (100-200 tests by experienced specialist). In a study in which 1,712 KANET tests were performed on 655 patients, the success rate of the test ranged between 91 and $95 \%$. Success rate for the assessment of particular signs of the KANET was between $88 \%$ for isolated eye blinking and $100 \%$ for mouth opening and isolated leg movement. The KANET had almost $100 \%$ negative predictive value. Interobserver agreement between two examiners for different components of the KANET were assessed by calculation of Kappa values, which were lowest for the facial expression $(K=0.68)$ and highest for the finger movements $(K=0.84)$, proving that KANET is a reliable method to be used with confidence in everyday clinical practice after appropriate education of the experienced examiner. What is more is that appropriate educational courses with certificate of completion 


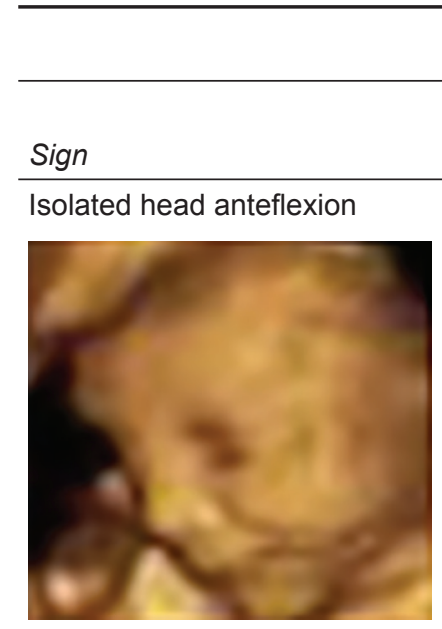

Cranial sutures and head circumference

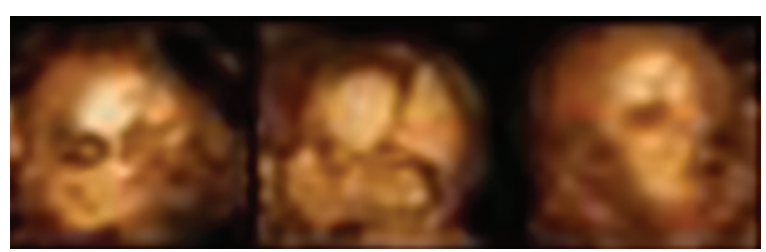

Isolated eye blinking

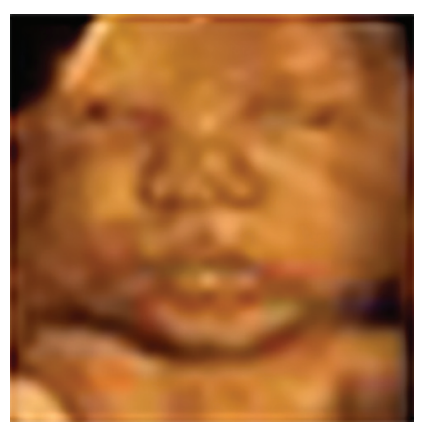

Facial alteration (grimace or tongue expulsion)

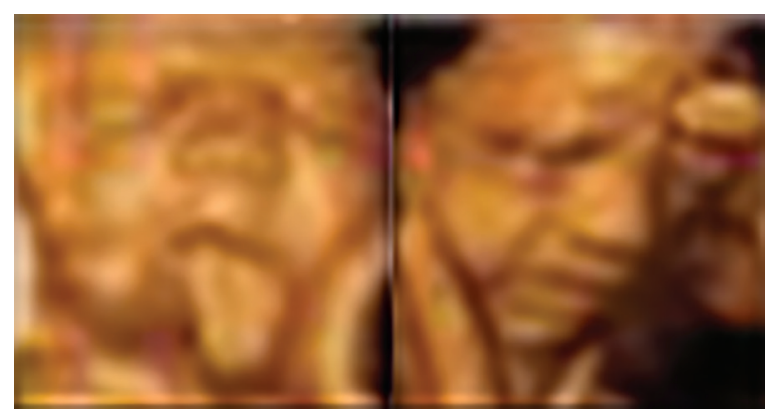

or

Mouth opening (yawning or mouthing)

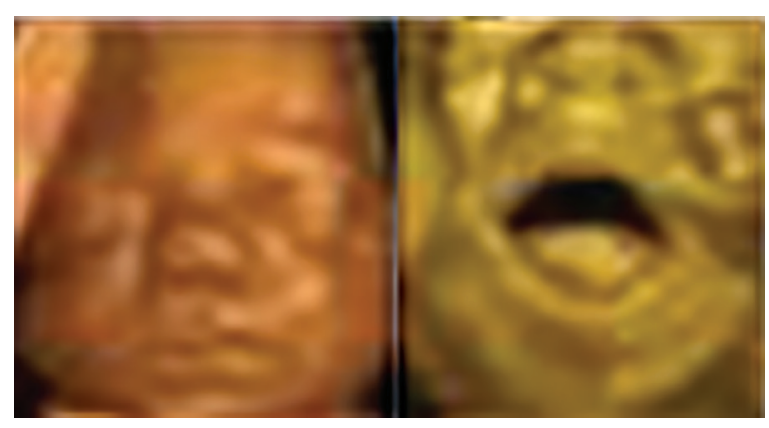

\section{Overlapping of} cranial sutures

Not present

Not present

Not fluent $(1-5$ times of alteration)
Normal cranial sutures with measurement of $\mathrm{HC}$ bellow or above the normal limit (-2 SD) according to GA

Not fluent (1-5 times of blinking)

Fluency ( $>5$ times of blinking)
Normal cranial

sutures

with normal measurement of $\mathrm{HC}$ according to $\mathrm{GA}$

$>3$ times of

movements) 
(Cont'd...)

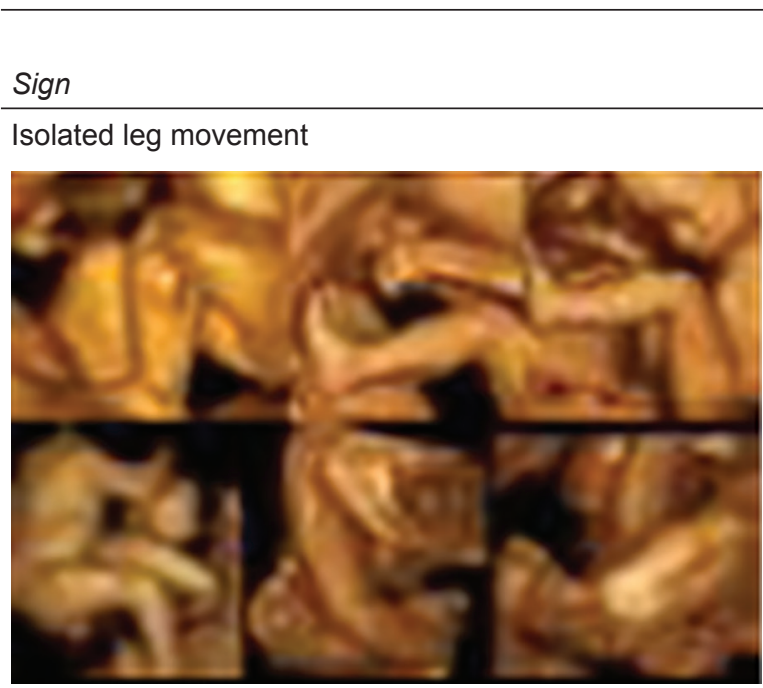

Isolated hand movement

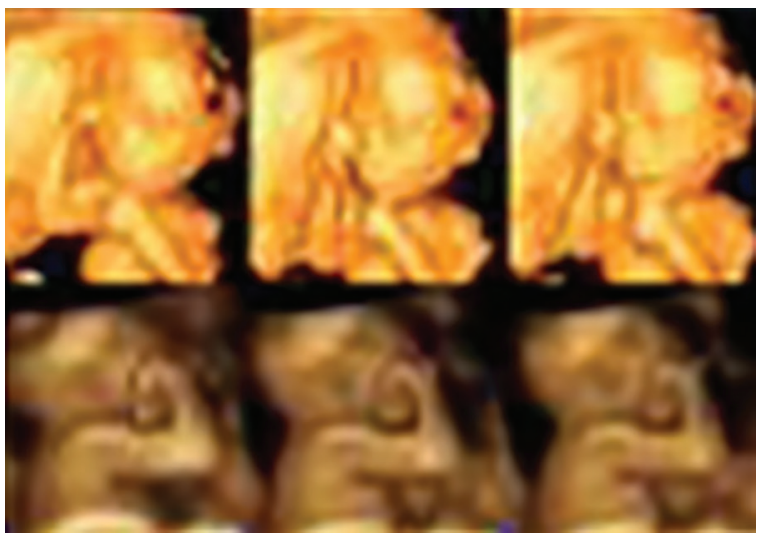

or

Hand and face movements

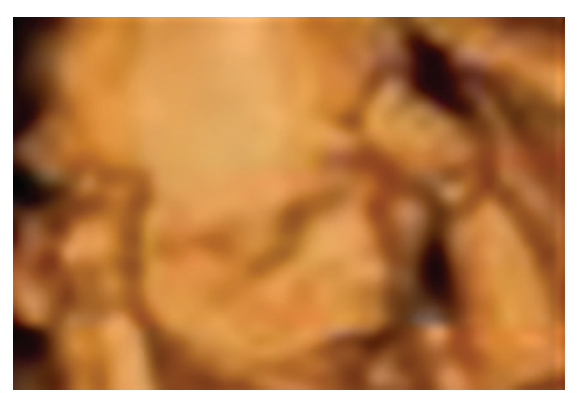

Fingers movements

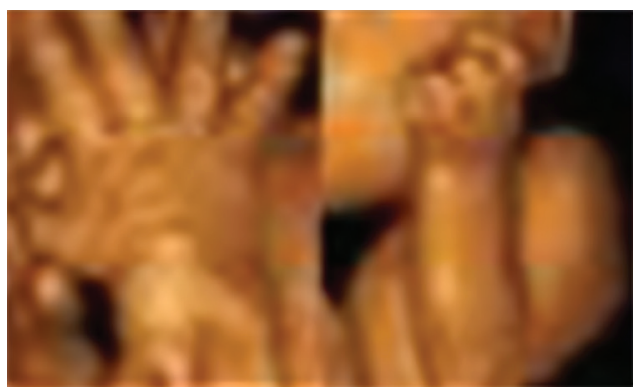

Gestalt perception of GMs

\begin{tabular}{|c|c|c|c|}
\hline \multicolumn{3}{|c|}{ score } & \multirow[b]{2}{*}{ Sign Score } \\
\hline 0 & 1 & 2 & \\
\hline Cramped & $\begin{array}{l}\text { Poor repertoire or } \\
\text { Small in range }(0-5 \\
\text { times of movement) }\end{array}$ & $\begin{array}{l}\text { Variable in full } \\
\text { range, many } \\
\text { alternation } \\
\text { (>5 times of } \\
\text { movements) }\end{array}$ & \\
\hline
\end{tabular}

Cramped or abrupt

Poor repertoire or Small in range $(0-5$ times of movement)

\section{Variable in full range many alternation ( $>5$ times of movement)}

Unilateral or bilateral clenched fist, (neurological thumb)
Definitely abnormal

\section{Cramped invariable} finger movements
Smooth and complex, variable finger movements
Borderline Normal

Total score 


\begin{tabular}{ll}
\hline & Table 3: KANET scoring system \\
& \\
\hline Total score & Interpretation \\
\hline $0-5$ & Abnormal \\
$6-9$ & Borderline \\
$10-16$ & Normal \\
\hline
\end{tabular}

on the performance of KANET are organized by the Ian Donald School of Ultrasound.

\section{Evidence of Prenatal Detection by the Application of the KANET according to Multicentric Studies}

The first form of KANET scoring system was applied by Andonotopo and Kurjak. ${ }^{55}$ Their aim was to assess whether facial expression and body movements could be of any diagnostic value regarding cerebral palsy $(\mathrm{CP})$ in growth-restricted fetuses. They studied 50 pregnancies with intrauterine growth restriction (IUGR) after 28 weeks of pregnancy. They noted decreased behavioral activity in the IUGR fetuses compared with non-IUGR. This preliminary study motivated further studies about the usefulness of 4D US for the assessment of fetal behavior. Introduction of KANET as a method could identify characteristics in fetal behavior or movement that manifested some degree of brain impairment. For the development of this test, several neonates with variable forms of neurological impairment were examined and compared with "normal" neonates. The idea was to try and identify similar differences during in utero life in order to diagnose brain impairment prenatally. The KANET was applied retrospectively in 100 low-risk pregnancies and all fetuses were assessed, and after delivery, with the score 14 to 20 characterized as normal. Then, the test was applied to 120 high-risk pregnancies according to the postnatal assessment, and neonates were divided into three groups: normal, mildly or moderately abnormal, and abnormal. According to the results, the scoring system was divided to prenatal score 14 to 20 (normal), 5 to 13 (mildly or moderately abnormal), and 0 to 5 (abnormal). From the abnormal cases, 4 were diagnosed with alobar holoprosencephaly, 1 with severe hydrocephaly, 1 with thanatotrophic dysplasia, and 4 cases with multiple severe structural abnormalities. Following this preliminary study (Table 4), many studies applied KANET and assessed its usefulness for the detection of neurological impairment during in utero life. ${ }^{25,32}$

In one of the studies out of 288 high-risk pregnancies, 7 abnormal cases were included and also 25 cases with borderline KANET score, yielding 32 fetuses at neurological risk. There were also 11 cases with abnormal KANET, of which 6 fetuses died in utero and 5 were terminated. The seven remaining neonates with abnormal KANET were followed up postnatally at 10 weeks and from these neonates, three had confirmed pathological ATNAT score postpartum. These three cases included a neonate with arthrogryposis, a neonate with cerebellar vermian complete aplasia, and one case with a history of $\mathrm{CP}$ in a previous pregnancy.

The main characteristic of these three cases were the facial expressions which appeared significantly diminished - these faces are characterized as masks due to lack of expressions noted at the time of US examination. The remaining four cases with pathological KANET did not show abnormal ATNAT postnatally, and the examiners characterized the neurological assessment as normal. These four cases included a case of ventriculomegaly, a case complicated by preeclampsia, one case with maternal thrombophilia, and one case complicated by oligohydramnios. From the 25 cases diagnosed with borderline KANET result, 22 neonates showed a borderline ATNAT score and were followed up, while the three remaining cases showed normal ATNAT result. These three cases were complicated by ventriculomegaly, chorioamnionitis, and maternal thrombocytopenia respectively. The cases with pathological prenatal score and normal postnatal ATNAT were characterized by the following risk factors: ventriculomegaly, Dandy-Walker malformation, skeletal dysplasia, increased amniotic fluid, gestational diabetes, hydrocephaly, thrombophilia, preeclampsia, achondroplasia, oligohydramnios, nonimmune hydrops, chorioamnionitis, growth restriction, Down's Syndrome, and thrombocytopenia.

From the three cases with pathological KANET at neonatal assessment with ATNAT 2 showed confirmed abnormal Prechtl's general movements (these were the cases with arthrogryposis and with cerebellar vermis aplasia), while there were six more cases, which were characterized as pathological (history of previous neonate with CP, Dandy-Walker syndrome, hydrocephaly, Down's Syndrome, ventriculomegaly, nonimmune hydrops). From the remaining 21 neonates, all of them had normal optimal or suboptimal general movements.

An interesting case was that of a fetus with acrania and by studying this pregnancy, they managed to document how fetal behavior altered from 20 weeks of gestation. The remarkable thing was that as pregnancy progressed and the control center of motoric activity shifted from the lower to the upper part, the KANET score was becoming lower and lower, suggesting that neurological damage in later pregnancy is possible. ${ }^{50}$

A study with 226 cases, ${ }^{54}$ including different study populations, identified three cases with pathological KANET. All three cases had chromosomal abnormalities and all three postnatally had also an abnormal ATNAT. Scores from antenatal KANET and postnatal ATNAT were compared between low- and high-risk groups, and showed differences between them, for 8 out of the 


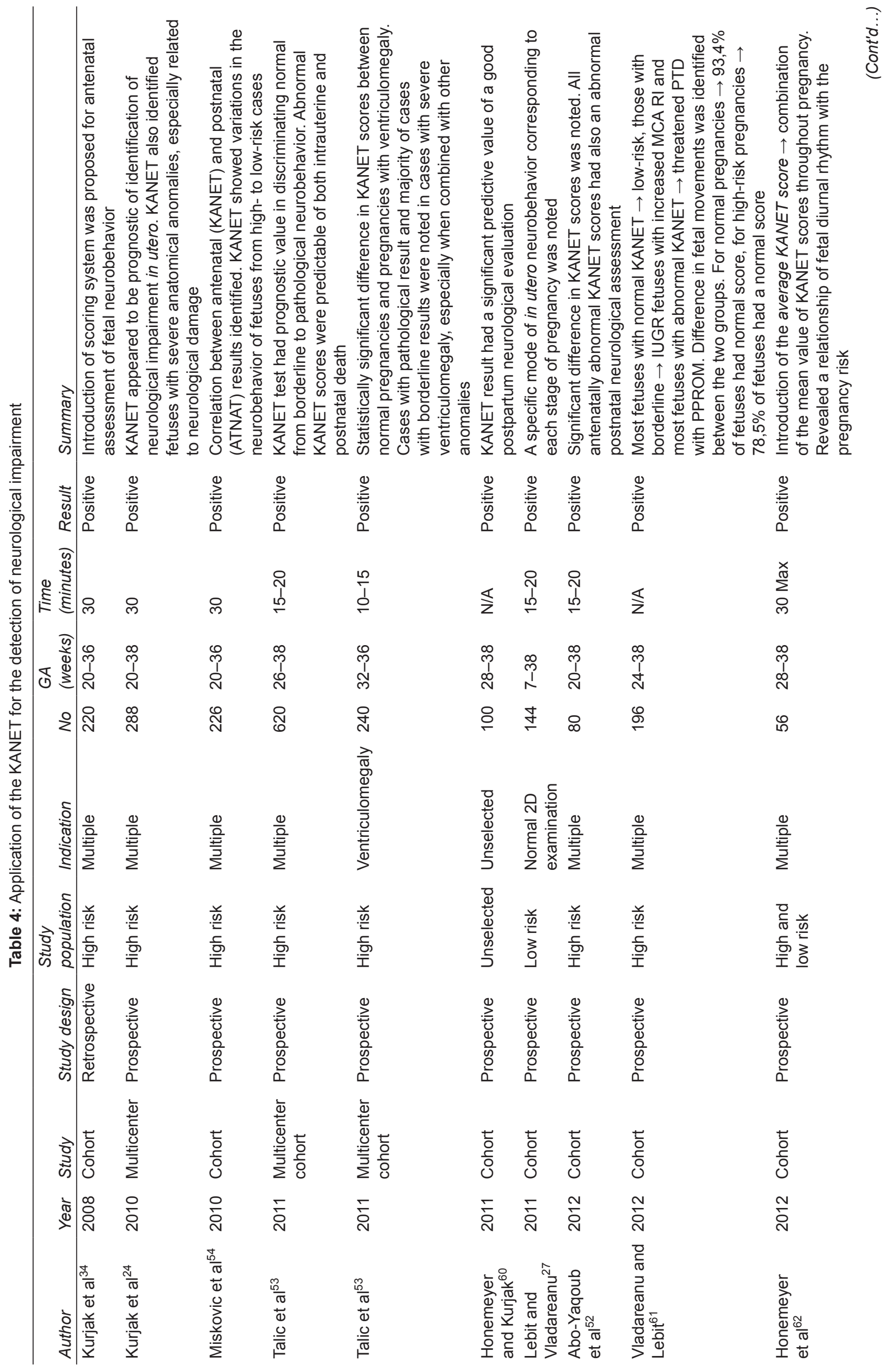


10 parameters-these included: head anteflexion, eye blinking, facial expressions-grimacing, tongue expulsion, mouth movement, such as yawning, jawing, swallowing-isolated hand movements, hand-to-face movements, fist and finger movements, and general movements.

The comparison of the two tests revealed correlation between them, proving that the neonatal exam (ATNAT) was a satisfactory confirmation of the prenatal US examination (KANET), stating that possibly with further studies, this antenatal test could offer useful information about the neurological status of the fetus and be applied in clinical practice.

The largest study of KANET ${ }^{53}$ includes 620 cases, of both low- and high-risk populations (100 low-risk and 520 high-risk cases). This study did not include fetuses with anatomical anomalies that were studied between 26 and 38 weeks of gestation. The high-risk group included the following cases: threatened preterm delivery with or without preterm premature rupture of membranes (PPROM), previous history of $\mathrm{CP}$, pregnancy hypertension, preeclampsia, gestational diabetes, IUGR, polyhydramnios, Rhesus alloimmunization, placental abruption, and maternal fever $>39^{\circ} \mathrm{C}$.

Analysis revealed differences in the average KANET scores between high- and low-risk groups. The most cases of pathological KANET were identified in the cases that were characterized by a previous history of CP (23.8\%), while the most cases of borderline KANET were noted in cases with maternal fever, which were possibly related to chorioamnionitis (56.4\%). The parameters of KANET that were more notably different between the two groups were overlapping cranial sutures, head circumference, isolated eye blinking, facial expressions, mouth movements, isolated hand movements, isolated leg movements, hand-to-face movements, finger movements, and general movements. This study concluded that an abnormal KANET score is related not only with an increased risk of both intrauterine and neonatal mortality, but also with an increased risk of neurological impairment. What they also mentioned is that KANET is indicative of not only normal, but also abnormal fetal neurobehavior, which can be demonstrated in postpartum life.

A study by Honemeyer and Kurjak ${ }^{60}$ with 100 cases, and a very good postnatal follow-up of the neonates, not only exactly at the time of delivery, before discharge from the hospital, but also at routine follow-up at 3 months of life, showed that a good KANET score confirms up to a great extent normal neurological examination of the neonate at the time of delivery and at 3 months of age. A study by Lebit and Vladareanu ${ }^{27}$ included 144 low-risk pregnancies, which they followed up antenatally from as early as 7 weeks up to 38 weeks, in order to define a specific pattern of fetal behavior that would be characterized 

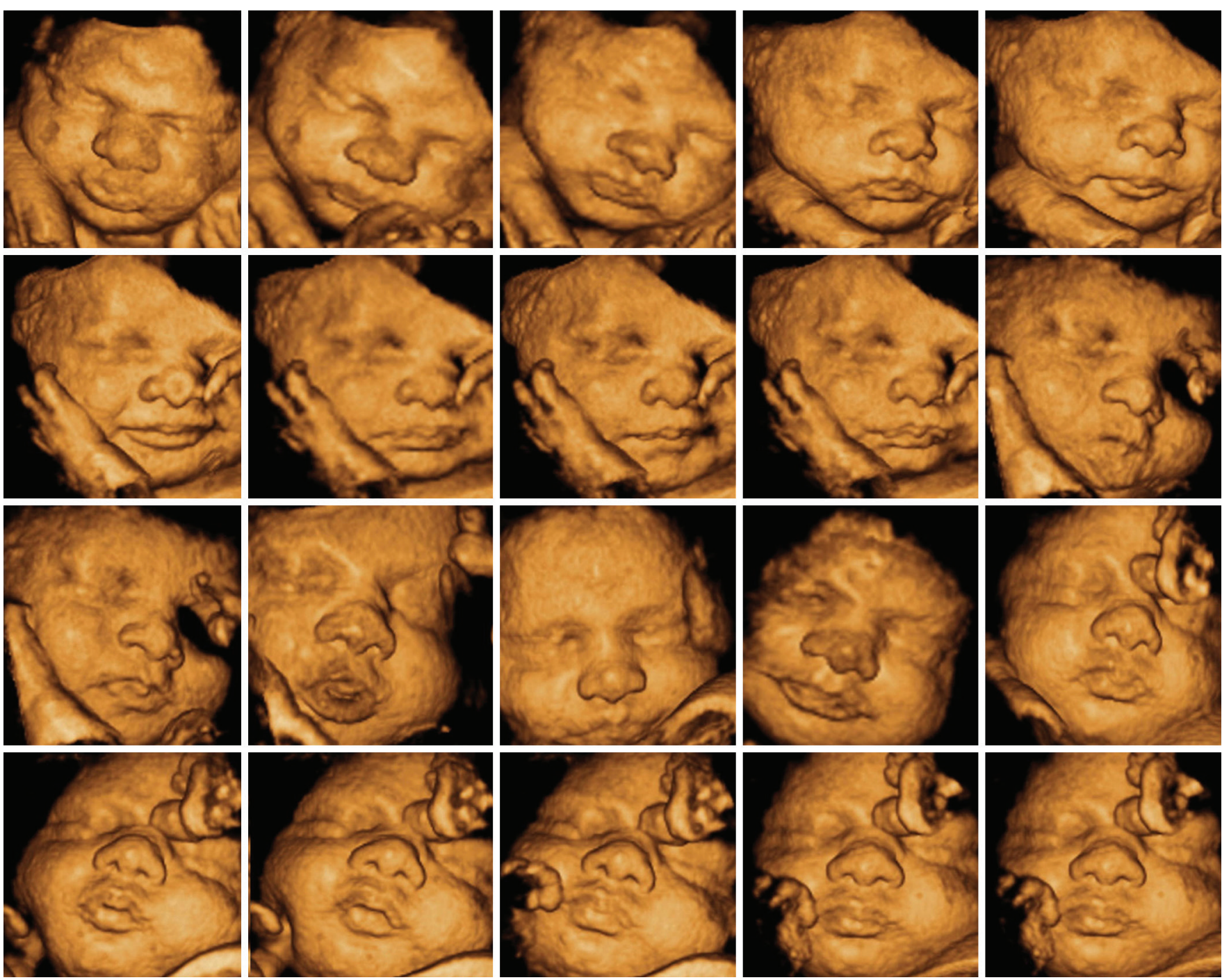

Fig. 7: Normal KANET test at 34 weeks of gestation

as normal and correspond to each trimester. It appears that during the first weeks of pregnancy, the number of fetal movements increase as does their complexity. In the second trimester, the fetal motoric activity increases in number and different types of movements develop. More detailed movements, such as facial grimacing and eye blinking tend to make their appearance during the middle of second trimester. Many women sustain that their perception of fetal movements decreases near term; that is because at that time, fetal movements indeed decline in frequency, as the duration of fetal rest periods increases as a result of fetal cerebral maturation rather than the fact, as many people believe, that the amniotic fluid decreases at the end of pregnancy. ${ }^{25,26}$ Fetal behavior may reflect the level of CNS maturation and integrity and, as a result, the KANET, which assesses fetal behavior, may offer useful information. ${ }^{27}$ A study which applied KANET in 140 fetuses with ventriculomegaly ${ }^{56}$ and compared them with 100 fetuses with normal CNS appearance during 32 to 36 weeks of gestation showed a big difference of abnormal KANET scores between the two groups (6\% abnormal KANET in the low risk-control group compared with $34.9 \%$ in the group with ventriculomegaly. The greatest the degree of ventriculomegaly is, the lowest is the KANET score, especially when other anomalies were present.

What is interesting is that no cases of pathological KANET score were identified when the degree of ventriculomegaly was mild or moderate and no other anomalies were present. The study showed agreement of prenatal KANET with the postpartum neonatal evaluation; also application of KANET in cases of ventriculomegaly offered the opportunity to identify fetuses who would not only have a structural anomaly, but also whose motoric activity would be affected, so that a complete assessment of the nervous system could be achieved, not only anatomically, but also functionally. That is extremely important especially in cases of ventriculomegaly; the importance of which and how it will affect a neonate is not always well understood.

A study ${ }^{52}$ of 40 cases with increased risk for neurological anomalies applied KANET between 20 and 38 weeks of gestation and compared the results with a 

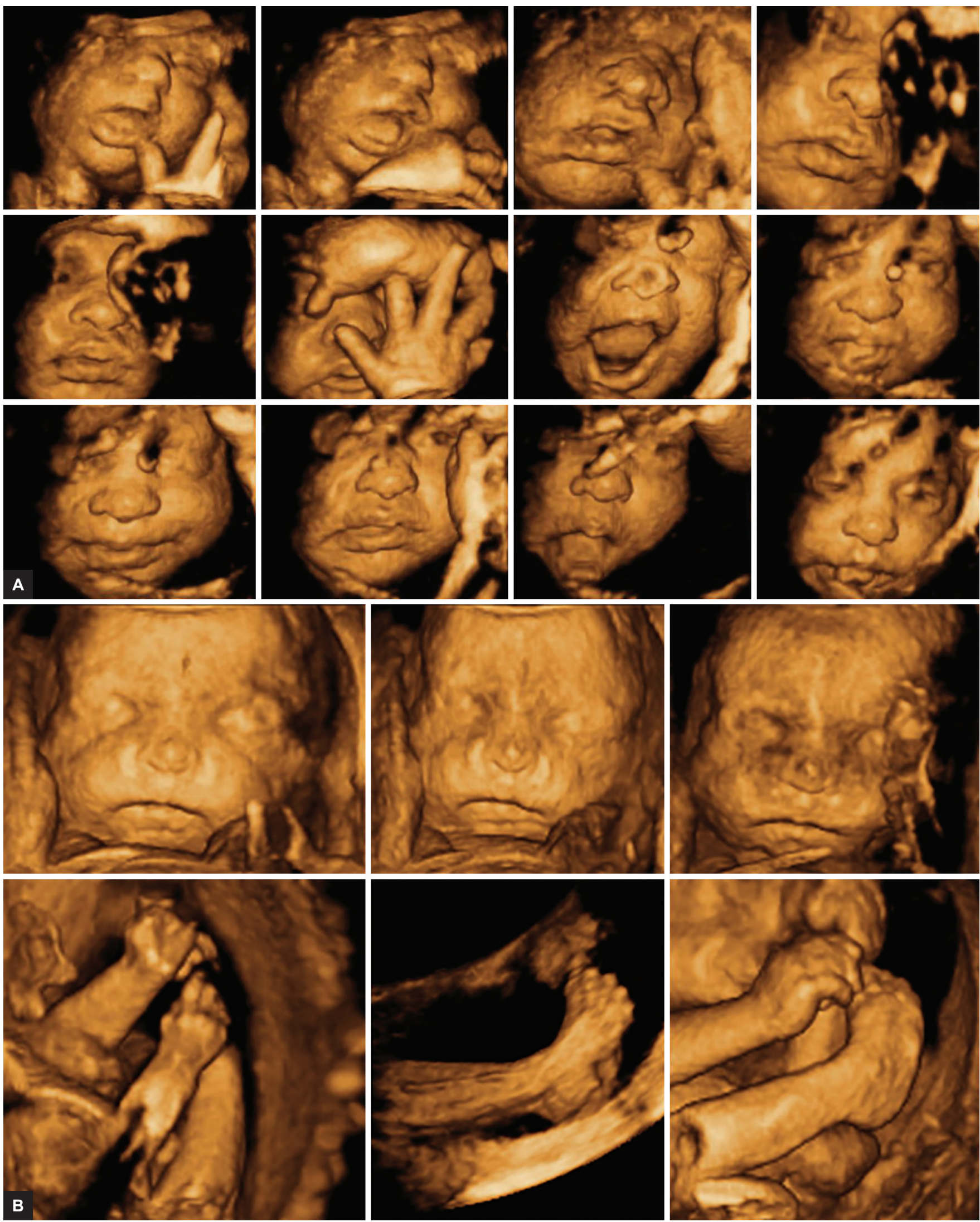

Figs $8 \mathrm{~A}$ and B: A complete KANET test - facial alterations, mouthing, eye blinking, and hand movement; and (B) Abnormal KANET score at 28 weeks of a fetus with severe hydranencephaly after cytomegalovirus infection. No facial alterations or mouth movements were identified ("frozen face or face-like mask"), fists remained clenched, and no leg movements were seen (right foot deviated inward - club foot) 

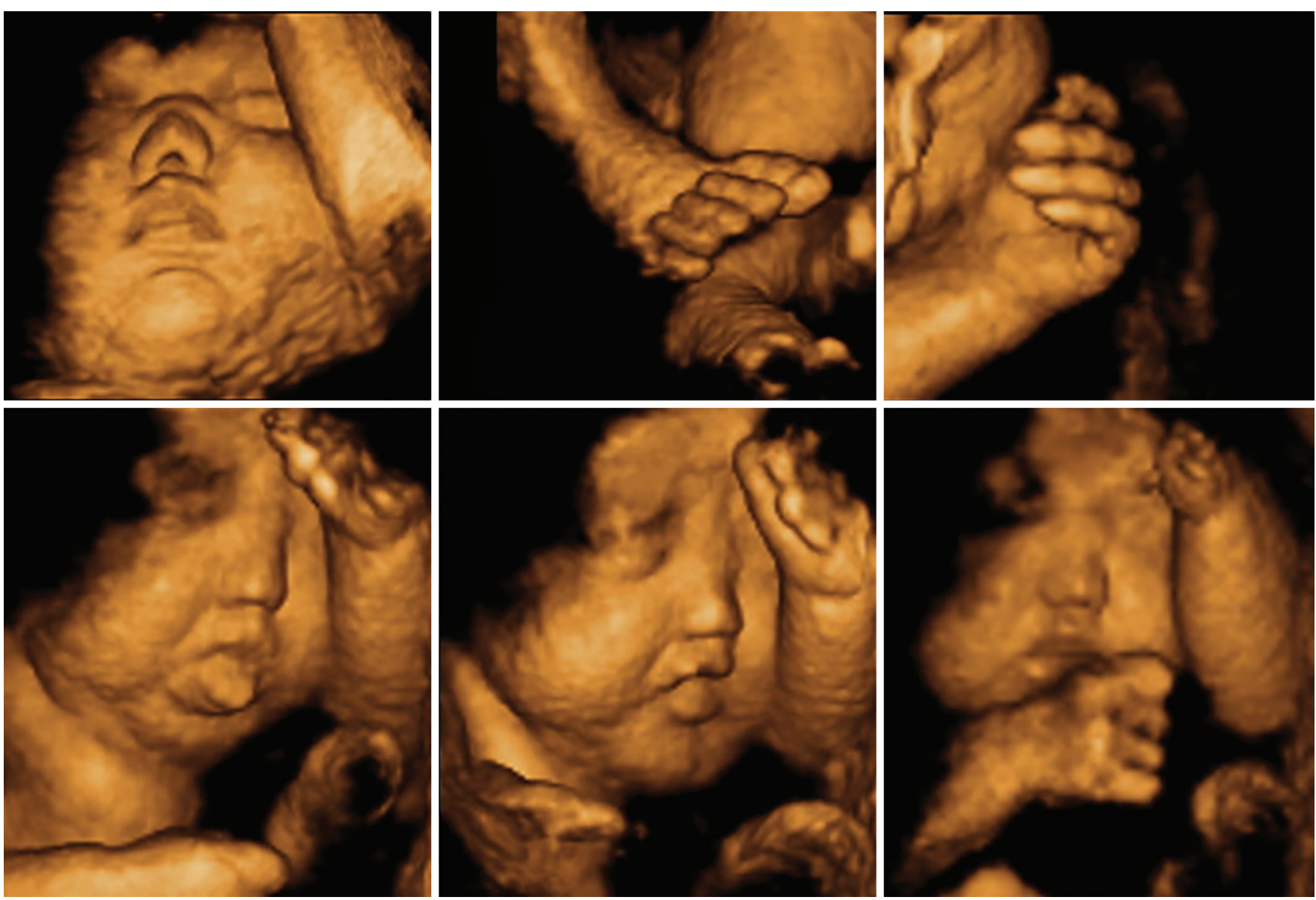

Fig. 9: Abnormal KANET score at 31 weeks of gestation of a fetus with semilobar holoprosencephaly. Mouth movements were identified (tongue expulsion), but otherwise, facial alterations were minimal and the KANET score was abnormal (KANET score $=4$ ). No leg movements were seen and neurological thumb was identified. Neonate died 3 days after delivery

control group of 40 low-risk cases. They aimed to define the usefulness and feasibility of $4 \mathrm{D}$ ultrasonography in the assessment of fetal neurobehavior and also in the prediction of neurological impairment.

The two groups had significant differences in their KANET scores, and the study showed that in all cases where the KANET score was abnormal, postnatally there was some degree of neurological impairment; while, when the KANET score was normal or even borderline, the neurological outcome postnatally was also normal. The parameters that were significantly different between the two groups were isolated head anteflexion, isolated eye blinking, facial expressions, mouth movements, isolated hand movements hand-to-face movements, finger movements, and general movements. Regarding isolated leg movements and cranial sutures, the difference was not significant.

Vladareanu et $\mathrm{al}^{61}$ applied KANET in 196 singleton pregnancies (61 low-risk and 135 at-risk patients) from 24 to 38 weeks. The study lasted for 3 years. Most fetuses in the study who obtained normal KANET scores belonged to the low-risk group. The majority of cases with borderline scores belonged to the IUGR group that also had high resistance index (RI) in the middle cerebral artery
(MCA), while the majority of cases with pathological KANET score belonged to cases of threatened preterm labor with PPROM.

There was statistical significant difference in fetal movements in the two groups. In normal pregnancies, most fetuses $(93.4 \%)$ achieved a normal KANET score compared with $78.5 \%$ of the fetuses from high-risk pregnancies. Borderline and abnormal scores were dominant in high-risk pregnancies. In the high-risk pregnancy group, the most abnormal KANET scores were noted in cases of threatened preterm delivery with PPROM (25\%). Most fetuses with pregnancies complicated by IUGR with MCA RI index changes and with hypertension above 160/100 mm Hg achieved borderline score (50\%). The highest percentage of normal fetal movements was found in pregnancies complicated by Rhesus alloimmunization without hydrops fetalis $(96 \%)$. The characteristics of reduced speed and amplitude were found in the threatened preterm delivery group. There was a reduction of both number and duration of general movements in the IUGR group. The IUGR fetuses moved less and their general movements were poorly organized. Alterations in the quality of fetal movements were accompanied by considerable decrease in the quantity of fetal movements. 

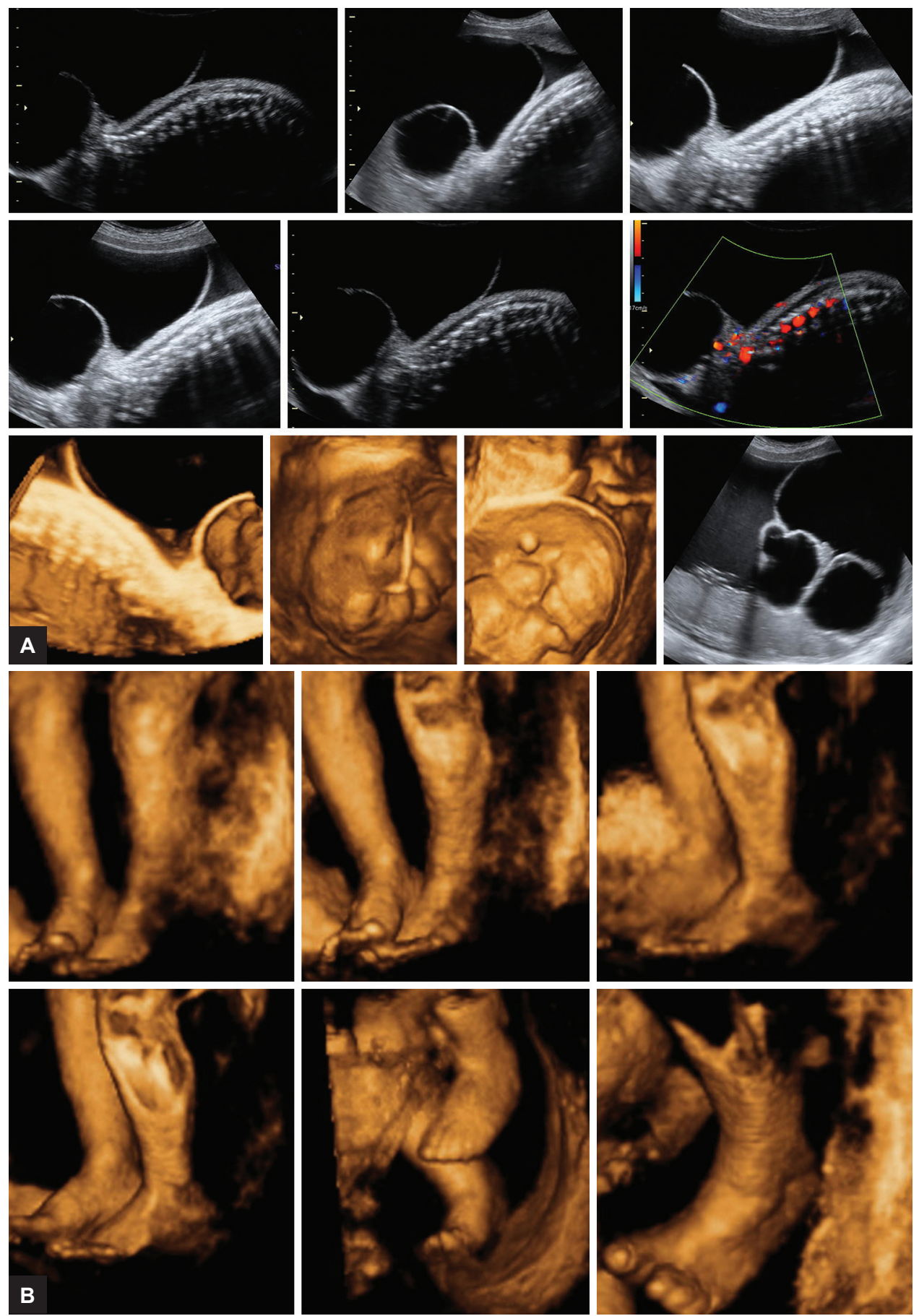

Figs 10A to B: Special application of KANET. This is a patient with sacrococcygeal teratoma. An US specialist experienced in KANET was asked to assess the integrity of the mobility of the lower extremities of the fetus. The experience acquired as KANET is applied in more and more cases, thus offering a wide knowledge of the in utero behavior and motoric activity of the fetus and giving answers to special problems

The authors concluded that KANET can be useful in the detection of neurological impairment that could become obvious during the antenatal or postnatal period. Honemeyer et al $^{62}$ studied 56 singleton pregnancies (24 low-risk and 32 high-risk cases) between 28 and 38 weeks of gestation and applied serial KANETs on them, performing a total of 117 tests in total. They did not identify any abnormal KANET scores, but two-thirds of the borderline scores occurred in the high-risk pregnancies. Because they performed more than one KANET in each pregnancy, they introduced the average KANET score, which was derived from the scores of each fetus during pregnancy. Only one fetus had a borderline average KANET score, and this fetus who belonged to the high-risk group was the only one out of 56 pregnancies who had an abnormal early neurological outcome. When the authors compared 

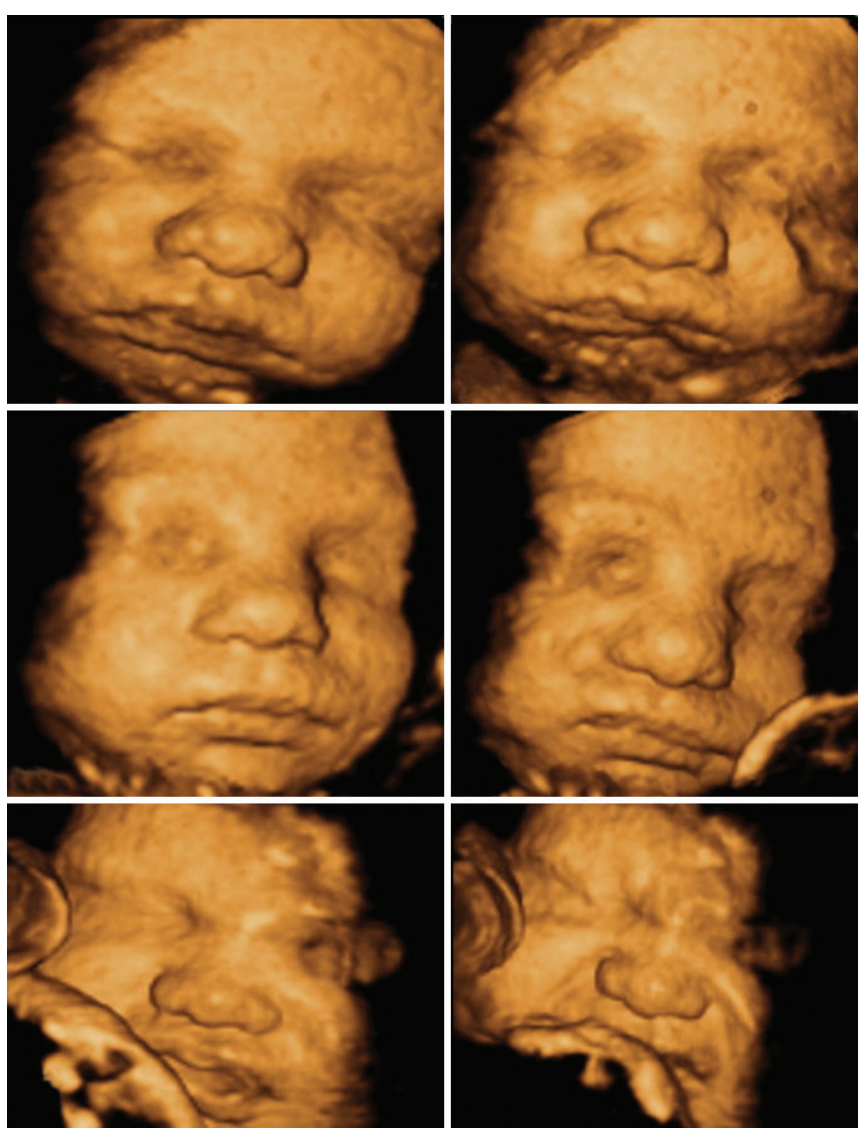

Fig. 11: KANET - facial alterations and grimacing

all the 18 borderline KANET scores with fetal diurnal rhythm based on maternal observation, they noticed that $89 \%$ of the borderline scores of the at-risk group were recorded at times that the mothers characterized them as active periods, compared with $33.3 \%$ in the low-risk pregnancies. The authors concluded that KANET is suggestive of expressing the risk for neurodevelopmental fetal disorders, but the connection of fetal diurnal rhythm and pregnancy risk status should be investigated further. Kurjak et $\mathrm{al}^{63}$ studied 869 high- and low-risk singleton pregnancies taking under consideration the results of the Doppler studies of umbilical and middle cerebral arteries, and noticed that fetal behavior was significantly different between the normal group and the following subgroups of fetuses: IUGR, gestational diabetes mellitus, threatened preterm birth, antepartum hemorrhage, maternal fever, sibling with $\mathrm{CP}$, and polyhydramnios. The authors concluded that their study showed a new clinical application of the KANET in early identification of fetuses prone to neurological impairment.

Athanasiadis et $\mathrm{al}^{74}$ studied with KANET, 152 pregnancies of both low and high risk. According to the maternal background risk, there were 78 low-risk and 74 high-risk pregnancies (12 with IUGR fetuses, 24 with diabetes mellitus, and 38 with preeclampsia. The study showed that the neurodevelopmental score was statistically significant higher in the low-risk group compared with the high-risk group $(\mathrm{p}<0.0004)$. The diabetes subgroup score was statistically significantly higher compared with the IUGR and the preeclampsia subgroup $(p=0.0001)$. The authors concluded that the neurodevelopment fetal assessment by 4D US appears to be a feasible technique in the evaluation of high-risk pregnancies and the detection of differences in these populations.

Neto ${ }^{79}$ performed a pilot study in Brazil by applying KANET to 17 high-risk pregnancies and 34 low-risk pregnancies and compared the results. He noticed that for KANET score 0,5 out of 8 parameters were significantly different: isolated head anteflexion, cranial sutures and head circumference, isolated hand movement or hand-toface movements, and isolated leg movement and fingers movements. All abnormal KANET results derived from high-risk pregnancies (17.6\%). No low-risk pregnancies presented with KANET score 0, concluding that there were important differences in fetal behavior between low- and high-risk pregnancies.

Hanaoka et $\mathrm{al}^{78}$ assessed with KANET, 89 Japanese (representative of Asians) and 78 Croatian (representative of Caucasians) pregnant women and studied the total value of KANET score and values of each parameter (eight parameters) in the different populations. Total KANET score was normal in both populations, but there was a significant difference in total KANET scores between Japanese and Croatian fetuses. When individual KANET parameters were compared, significant differences were observed in four fetal movements (isolated head anteflexion, isolated eye blinking, facial alteration or mouth opening, and isolated leg movement). No significant differences were noted in the four other parameters (cranial suture and head circumference, isolated hand movement or hand-to-face movements, fingers movements, and gestalt of general movements), showing that ethnicity should be considered when evaluating fetal behavior, especially during assessment of fetal facial expressions. The authors concluded that although there was a difference in the total KANET score between Japanese and Croatian populations, all the scores in both groups were within normal range proving that ethnical differences in fetal behavior do not affect the total KANET score, but close follow-up should be continued in some borderline cases.

\section{Advantages of Early Detection of Neurodevelopmental Disorders in utero}

Once the diagnosis of neurological impairment is made in neonates, the interventions available in everyday clinical practice are very limited and usually they prove to be ineffective. The KANET offers the possibility of very early, prenatal detection of fetus at-risk for neurological problems. This very early detection of these high-risk fetuses 
may be the key for the management of these cases, as the earlier you have a diagnosis, the earlier you may possibly intervene and, as a result, increase the possibility if not for treatment, for an improved outcome. It has been suggested, for example, for many years, that early application of physiotherapy can be of some significance and that it can improve neurodevelopmental outcome. In a Cochrane meta-analysis, it has been stated that early intervention programs for preterm infants have a positive influence on cognitive and motor outcomes during infancy, with the cognitive benefits persisting into preschool age. Of course, further research is needed to determine which early developmental interventions really make a difference in improving the cognitive or motoric functions of neonates. In one of the programs, the primary caregivers have been educated about evidence-based interventions for improving infant self-regulation, postural stability, coordination and strength, parent mental health, and the parent-infant relationship. A therapy team consisting of a physiotherapist and psychologist delivered the nine sessions of the program (each session was 1.52 hours long) in the family home over the infant's first year of life. Infants and their caregivers have selective long-term benefits, with caregivers experiencing fewer anxiety symptoms and lower odds of an anxiety disorder and preschoolers showing fewer internalizing behavior problems. It is obvious that we do not have many effective treatment options for cases of neurological impairment, but it appears that the earlier you apply these treatments, the better the results. Also, the earlier you have a diagnosis, then indeed you can apply earlier these treatments to the correct group of people, and this is an area where definitely KANET can be a pioneer. ${ }^{75,76}$

\section{Experience of KANET so far - Already 10 Years}

So far, KANET has been proven a strong diagnostic method of great potential, particularly for the detection of problems that were inaccessible by any other method until now, such as fetal brain impairment and neurodevelopmental alterations. ${ }^{41}$ Of course as a new method, it has to be further tested and more, larger studies are required in order to draw safe conclusions and for this test to be ready for introduction in clinical practice.

So far, studies have shown that KANET is useful for the study of fetal neurobehavioral patients, offering the opportunity to detect antenatally fetuses with severe neurological problems ${ }^{26,48,51}$; also, the introduction of KANET in clinical practice for the assessment of high-risk pregnancies is feasible. Ongoing studies aim to further investigate the potential of this new method setting the guidelines for a complete fetal neurosonography and neurobehavior assessment. ${ }^{64}$ The continuous knowledge that we gain by studying fetal neurobehavior in a systematic way with the application of a standardized method, such as KANET, in combination with the unrelenting technological advantage of 4D ultrasonography gives the impression that in the near future, perinatal medicine will be able to study in explicit detail the functional development and maturation of the fetal nervous system, something that until today has not been achieved.

\section{Neonatal Aspects of Fetal Behavior}

As we can learn from the previously presented data, neurobehavior is the expression of development of the CNS (in particular, the brain), which is a complex ongoing process throughout gestation and after birth. ${ }^{80-}$ ${ }^{82}$ It is important to understand how CNS produces different kinds of movements and which of them are important for the assessment of disturbed CNS development. Fetuses and newborns exhibit a large number of endogenously generated motor patterns, which are presumably produced by central pattern generators located in different parts of the brain. ${ }^{83}$ Moreover, substantial indications suggest that spontaneous activity is a more sensitive indicator of brain dysfunction than reactivity to sensory stimuli in reflex testing. ${ }^{83}$ It has been demonstrated that in newborn infants affected by different brain lesions, spontaneous motility does not change in quantity, but it loses its elegance, fluency, and complexity. ${ }^{84}$ As the development of the brain is a unique and continuing process throughout the gestation and after birth, it is expected that there is also continuity of fetal to neonatal movements, which are the best functional indicators of developmental processes of the brain. ${ }^{80-84}$

Weight, length, and head circumference at birth were not significantly associated with neurodevelopmental outcomes at the age of two for small for gestational age (SGA) or appropriate for gestational age (AGA) very low-birth weight (VLBW) children. ${ }^{85}$ However, weight and length at age two correlated with psychomotor developmental index in SGA and AGA children. ${ }^{85}$ These findings indicated an association between postnatal growth and neurodevelopmental outcome. ${ }^{6}$ Thus, AGA children with catch down growth had the highest risk for mental retardation, motor delay, and CP among all VLBW children. ${ }^{85}$ These findings were mostly independent of the diagnosis of $\mathrm{CP}^{6}$ The origin of $\mathrm{CP}$ in children born at-term was considered to be prenatal in $38 \%$, peri/neonatal in 35\%, and unclassifiable in $27 \%$, while in children born preterm, it was 17, 49, and 33\% respectively. ${ }^{86-88}$

Heinz Prechtl's work enabled that spontaneous motility during human development has been brought into 
focus of interest of many perinatologists prenatally and developmental neourologists postnatally. ${ }^{89,90}$ According to the research preceding Prechtl's ingenious idea, during the development of the individual, the functional repertoire of the developing neural structure must meet the requirements of the organism and its environment. ${ }^{89,90}$ This concept of ontogenetic adaptation fits excellently to the development of human organism, which is during each developmental stage adapted to the internal and external requirements. ${ }^{89,90}$ The most important among those movements are the so-called general movements involving the whole body in a variable sequence of arm, leg, neck, and trunk movements, with a gradual beginning and the end. ${ }^{89,90}$ The general movements are called fetal or preterm from 28 to 36 to 38 weeks of postmenstrual age, while after that, we have at least two types of movements: writhing present till 46 to 52 weeks of postmenstrual age and fidgety movements present till 54 to 58 weeks of postmenstrual age. ${ }^{89,90}$ According to Hadders-Algra, ${ }^{90}$ general movements according to their fluency and complexity could be classified as normaloptimal, normal-suboptimal, mildly abnormal, and definitely abnormal. Abnormality of general movement has, however, limited value in the prediction of neurodevelopmental outcome in preschool children. ${ }^{91}$

Are we approaching the era when there will be an applicable neurological test for fetus and assessment of the neonate will be just the continuation ${ }^{63,92}$ This is still not easy question to answer, because even postnatally, there are several neurological methods of evaluation, while in utero we are dealing with more complicated situations and a less mature brain. ${ }^{63,92}$ Whether neonatal assessment of neurologically impaired fetuses could bring some new insights into their prenatal neurological status is still unclear and to be investigated. ${ }^{6,93}$ A new scoring system for prenatal neurological assessment of the fetus proposed by Kurjak et al. will give some new possibilities to detect fetuses at high neurological risk, although it is obvious that dynamic and complicated processes of functional CNS development are not easy to investigate. ${ }^{75}$ Besides that, there is an issue of different environments of fetal and neonatal development in term of the influence of the gravity. Data concerning the influence of the gravity on fetal motor development are contradictory. The concept that the fetus floats in a state of weightlessness cannot be applied to the whole of pregnancy, as after the fetus is confined to the uterus, it is exposed to the force of gravity. ${ }^{94-96}$ The fetus is not in significant contact with the walls of the amniotic sac until the very end of pregnancy, and sensory input arising from antigravity activity is absent, which is similar to the conditions of microgravity. ${ }^{97}$ Certain level of mechanical stress is necessary for the physiological development of the fetus. Along with muscle activity, gravitational loading also causes this mechanical stress. ${ }^{97}$ Buoyant forces apparently decrease fetal weight and in this way, they reduce the effect of gravitation on the musculoskeletal system. ${ }^{97}$ The development of antigravity muscular control is critical to normal motor development during the first year of life. After birth, the newborn is exposed to the $1 \mathrm{G}$ environment. Movement against gravity begins during the first month of life, and by four months of age, increased flexion control balances the strong extensor muscle patterns. ${ }^{97}$ Adequate development of trunk flexion and extension is a prerequisite to the development of anterior and posterior pelvic tilting, lateral trunk flexion, and trunk elongation. ${ }^{97}$ These components enable the child to develop weight shifting, which, in turn, stimulates righting and equilibrium responses. ${ }^{97}$

Concerning the continuity from fetus to neonate in terms of neurobehavior, it could be concluded that fetus and neonate are the same persons in different environments. While in the womb, fetus is protected from the gravity, which is not so important for its neurodevelopment, postnatally, the neonate is exposed to gravity during the labor and from the first moments of autonomous life. Development of motor control is highly dependent on antigravity forces enabling erect posture of infant or young child. These environmental differences should be kept in mind during prenatal as well as postnatal assessment. This could be one of the reasons why assessment of general movement is not considered as the reliable test for the long-term prediction of neurodevelopmental outcome.

\section{CONCLUSION}

One of the greatest challenges of obstetrical ultrasonography is the better understanding of fetal neurological function, a field with still many unanswered questions. The pathogenesis of major neurological conditions, such as CP, are not adequately understood and falsely attributed to accidents during labor, although it has been proven that the majority of $\mathrm{CP}$ cases originate sometime during in utero life and are not related to intrapartum events. The distinction between normal and abnormal fetal neurological behaviors and the development of an accurate method for the assessment of the function of fetal nervous system are great challenges in obstetrics; however, that was made possible with the introduction of 4 D US, which offered the opportunity to study the fetus in real time and with explicit detail.

It has been proven by multicentric studies that it is possible with the application of KANET test to assess fetal behavior in utero, so that in many cases, we can have 
an accurate diagnosis regarding some functional neurological abnormalities of fetuses. The KANET is the first method that applied 4D US for the assessment of the fetus in the same way that a neonate is assessed neurologically after birth by neonatologists. The KANET offers an objective scoring system that divides the fetuses according to the severity of the US findings, and studies show that it can identify fetal signs that could predict its neurological development. What is more is in cases of anatomical findings of uncertain significance and consequences on the neurological integrity of the fetus, like for example, in cases of ventriculomegaly, it offers the possibility of a more complete assessment of the fetus and, therefore, a more comprehensive counseling of the couples with an affected fetus.

The KANET is currently used by many centers in everyday clinical practice as the investigational tool for normal and high-risk fetuses. It has acceptable sensitivity and specificity, adequate positive and negative predictive values, inter- and intra-observer reliability, and can be easily learned by US specialists with access to 4D US machines. The aim of the KANET is to be widely applied in clinical practice for the selective screening of fetuses with moderate and high neurological risk; hopefully, the early detection of these fetuses would allow at last the diagnosis of severe cases in utero and also an early intervention that could improve the outcome for these neonates.

\section{REFERENCES}

1. Yigiter AB, Kavak ZN. Normal standards of fetal behavior assessed by four-dimensional sonography. J Matern Fetal Neonatal Med 2006 Nov;19(11):707-721.

2. Rees S, Harding R. Brain development during fetal life: influences of the intra-uterine environment. Neurosci Lett 2004 May;361(1-3):111-114.

3. Joseph R. Fetal brain and cognitive development. Dev Rev 1999;20:81-98.

4. Kurjak A, Carrera JM, Stanojevic M, Andonotopo W, Azumendi G, Scazzocchio E, Medic M, Salihagic-Kadic A. The role of $4 \mathrm{D}$ sonography in the neurological assessment of early human development. Ultrasound Rev Obstet Gynecol 2004;4:148-159.

5. Eidelman, AI. The living fetus e dilemmas in treatment at the edge of viability. In: Blazer S, Zimmer EZ, editors. The embryo: scientific discovery and medical ethics. Basel: Karger; 2005. p. 351e70.

6. Stanojevic M, Zaputovic S, Bosnjak AP. Continuity between fetal and neonatal neurobehavior. Semin Fetal Neonatal Med 2012 Dec;17(6):324-329.

7. Haak P, Lenski M, Hidecker MJ, Li M, Paneth N. Cerebral palsy and aging. Dev Med Child Neurol 2009 Oct;51 (Suppl 4): 16-23.

8. Einspieler C, Prechtl HF. Prechtl's assessment of general movements: a diagnostic tool for the functional assessment of the young nervous system. Ment Retard Dev Disabil Res Rev 2005 Feb;11(1):61-67.

9. Salihagic-Kadic A, Kurjak A, Medić M, Andonotopo W, Azumendi G. New data about embryonic and fetal neurodevelopment and behavior obtained by 3D and 4D sonography. J Perinat Med 2005 Dec;33(6):478-490.

10. Moster D, Wilcox AJ, Vollset SE, Markestad T, Lie RT. Cerebral palsy among term and postterm births. JAMA 2010 Sep;304(9):976-982.

11. Almli CR, Ball RH, Wheeler ME. Human fetal and neonatal movement patterns: gender difference and fetal-to-neonatal continuity. Dev Psychobiol 2001 May;38(4):252-273.

12. DiPietro JA, Bronstein MH, Costigan KA, Pressman EK, Hahn CS, Painter K, Smith BA, Yi LJ. What does fetal movement predict about behavior during the first two years of life? Dev Psychobiol 2002 May;40(4):358-371.

13. DiPetro JA, Hodson DM, Costigan KA, Johnson TR. Fetal antecedents of infant temperament. Child Dev 1996 Oct;67(5):2568-2583.

14. DiPietro JA, Costigan KA, Pressman EK. Fetal state concordance predicts infant state regulation. Early Hum Dev 2002 Jun;68(1):1-13.

15. Thoman EB, Denenberg VH, Sievel J, Zeidner LP, Becker P. State organization in neonate: developmental inconsistency indicates risk for developmental dysfunction. Neuropediatrics 1981 Feb;12(1):45-54.

16. St James-Roberts I, Menon-Johansson P. Predicting infant crying from fetal movement data: an exploratory study. Early Hum Dev 1999 Feb;54(1):55-62.

17. Einspieler C, Prechtl HF, Ferrari F. The qualitative assessment of general movements in preterm, term and young infants-review of the methodology. Early Hum Dev 1997 Nov;50(1):47-60.

18. Precht HF. Qualitative changes of spontaneous movements in fetus and preterm infant are a marker of neurological dysfunction. Early Hum Dev 1990 Sep;23(3):151-158.

19. de Vries JI, Visser GH, Prechtl HF. The emergence of fetal behaviour. II. Quantitative aspects. Early Hum Dev 1985 Nov;12(2):99-120.

20. de Vries JI, Visser GH, Prechtl HF. The emergence of fetal behaviour. III. Individual differences and consistencies. Early Hum Dev 1988 Jan;16(1):85-103.

21. de Vries JI, Visser GH, Prechtl HF. The emergence of fetal behaviour. I. Qualitative aspects. Early Hum Dev 1982 Dec;7(4):301-322.

22. Nijhuis, JG. Fetal behaviour: developmental and perinatal aspects. Oxford: Oxford University Press; 1992.

23. Prechtl HF. State of the art of a new functional assessment of the young nervous system. An early predictor of cerebral palsy. Early Hum Dev 1997 Nov;50(1):1-11.

24. Kurjak A, Luetic AT. Fetal neurobehavior assessed by threedimensional/four dimensional sonography. Zdrav Vestn 2010 Nov;79:790-799.

25. Salihagic-Kadic A, Medić M, Kurjak A, Andonotopo W, Azumendi G, Hafner T, Milenković D. 4D sonography in the assessment of fetal functional neurodevelopment and behavioural patterns. Ultrasound Rev Obstet Gynecol 2005; 5:1-15.

26. Kurjak A, Pooh RK, Tikvica A, Stanojevic M. Assessment of fetal neurobehavior by 3D/4D ultrasound. Fetal Neurol 2009;2009:222-250. 
27. Lebit DF, Vladareanu PD. The role of $4 \mathrm{D}$ ultrasound in the assessment of fetal behaviour. Maedica (Buchar) 2011 Apr;6(2):120-127.

28. Merz E, Abramowicz JS. 3D/4D ultrasound in prenatal diagnosis: Is it time for routine use? Clin Obstet Gynecol 2012 Mar;55(1):336-351.

29. Kurjak A, Vecek N, Hafner T, Bozek T, Funduk-Kurjak B, Ujevic B. Prenatal diagnosis: what does four-dimensional ultrasound add? J Perinat Med 2002 Feb;30(1):57-62.

30. Kurjak, A.; Vecek, N.; Kupesic, S.; Azumendi, G.; Solak, M. Four-dimensional ultrasound: how much does it improve perinatal practice? In: Carrera JM, Chervenak FA, Kurjak A, editors. Controversies in perinatal medicine, studies on the fetus as a patient. New York: Parthenon Publishing; 2003. p. 222.

31. Andonotopo W, Stanojevic M, Kurjak A, Azumendi G, Carrera JM. Assessment of fetal behavior and general movements by four-dimensional sonography. Ultras Rev Obstet Gynecol 2004 Jun;4(2):103-114.

32. Kurjak A, Carrera J, Medic M, Azumendi G, Andonotopo W, Stanojevic M. The antenatal development of fetal behavioral patterns assessed by four-dimensional sonography. J Matern Fetal Neonatal Med 2005 Jun;17(6):401-416.

33. Kurjak A, Miskovic B, Andonotopo W, Stanojevic M, Azumendi G, Vrcic H. How useful is 3D and 4D ultrasound in perinatal medicine? J Perinat Med 2007 Feb;35(1):10-27.

34. Kurjak A, Tikvica A, Stanojevic M, Miskovic B, Ahmed B, Azumendi G, Di Renzo GC. The assessment of fetal neurobehavior by three-dimensional and four-dimensional ultrasound. J Matern Fetal Neonatal Med 2008 Oct;21(10):675-684.

35. MorokumaS, Fukushima K, Yumoto Y,Uchimura M, Fujiwara A, Matsumoto M, Satoh S, Nakano H. Simplified ultrasound screening for fetal brain function based on behavioral pattern. Early Hum Dev 2007 Mar;83(3):177-181.

36. Kurjak A, Miskovic B, Stanojevic M, Amiel-Tison C, Ahmed B, Azumendi G, Vasilj O, Andonotopo W, Turudic T, SalihagicKadic A. New scoring system for fetal neurobehavior assessed by three- and four-dimensional sonography. J Perinat Med 2008 Feb;36(1):73-81.

37. Gosselin J, Gahagan S, Amiel-Tison C. The Amiel-Tison Neurological Assessment at Term: conceptual and methodological continuity in the course of follow-up. Ment Retard Dev Disabil Res Rev 2005 Feb;11(1):34-51.

38. Amiel-Tison C, Gosselin J, Kurjak A. Neurosonography in the second half of fetal life: a neonatologist's point of view. J Perinat Med 2006 Dec;34(6):437-446.

39. Tomasovic S, Predojevic M. 4D ultrasound - medical devices for recent advances on the etiology of cerebral palsy. Acta Inform Med 2011 Dec;19(4):228-234.

40. Kurjak A, Stanojevic M, Andonotopo W, Scazzocchio-Duenas E, Azumendi G, Carrera JM. Fetal behavior assessed in all three trimesters of normal pregnancy by four-dimensional ultrasonography. Croat Med J 2005 Oct;46(5):772-780.

41. Stanojevic M, Kurjak A, Salihagić-Kadic A, VasiljO, Miskovic B, Shaddad AN, Ahmed B, Tomasović S. Neurobehavioral continuity from fetus to neonate. J Perinat Med 2011 Mar;39(2): 171-177.

42. Kurjak A, Andonotopo W, Hafner T, Salihagic Kadic A, Stanojevic M, Azumendi G, Ahmed B, Carrera JM, Troyano JM. Normal standards for fetal neurobehavioral developments-longitudinal quantification by four-dimensional sonography. J Perinat Med 2006 Feb;34(1):56-65.
43. Stanojevic M, Talic A, Miskovic B, Vasilj O, Shaddad AN, Ahmed B, Salihagic Kadic A, Predojevic M, Vladareanu R, Lebit D, et al. An attempt to standardize Kurjak's antenatal neurodevelopmental test: Osaka Consensus Statement. Donald School J Ultrasound Obstet Gynecol 2011 Oct-Dec;5(4): 317-329.

44. Pooh RK, Pooh KH. Fetal ventriculomegaly. Donald School J Ultrasound Obstet Gynecol 2007;2(2):40-46.

45. Kurjak A, Ahmed B, Abo-Yaquab S, Younis M, Saleh H, Shaddad AN, Vasilj O, Al Bahar AJ, Miskovic B, Khenyab N. An attempt to introduce neurological test for fetus based on 3D and 4D sonography. Donald School J Ultrasound Obstet Gynecol 2008 Oct-Dec;2(4):29-34.

46. Kuno A, Akiyama M, Yamashiro C, Tanaka H, Yanagihara T, Hata T. Three-dimensional sonographic assessment of fetal behavior in the early second trimester of pregnancy. J Ultrasound Med 2001 Dec;20(12):1271-1275.

47. Koyanagi T, Horimoto N, Maeda H, Kukita J, Minami T, Ueda K, Nakano H. Abnormal behavioral patterns in the human fetus at term: correlation with lesion sites in the central nervous system after birth. J Child Neurol 1993 Jan;8(1): 19-26.

48. Kurjak A, Stanojevic M, Andonotopo W, Salihagic-Kadic A, Carrera JM, Azumendi G. Behavioral pattern continuity from prenatal to postnatal life-a study by four-dimensional (4D) ultrasonography. J Perinat Med 2004 Feb;32(4):346-353.

49. Stanojevic M, Kurjak A. Continuity between fetal and neonatal neurobehavior. Donald School J Ultrasound Obstet Gynecol 2008 Jul-Sep;2(3):64-75.

50. Kurjak A, Abo-Yaqoub S, Stanojevic M, Yigiter AB, Vasilj $O$, Lebit D, Shaddad AN, Ahmed B, Kavak ZN, Miskovic B, et al. The potential of $4 \mathrm{D}$ sonography in the assessment of fetal neurobehavior-multicentric study in high-risk pregnancies. J Perinat Med 2010 Jan;38(1):77-82.

51. Andonotopo W, Kurjak A, Kosuta MI. Behavior of an anencephalic fetus studied by 4D sonography. J Matern Fetal Neonatal Med 2005 Feb;17(2):165-168.

52. Abo-Yaqoub S, Kurjak A, Mohammed AB, Shadad A, Abdel-Maaboud M. The role of 4-D ultrasonography in prenatal assessment of fetal neurobehaviour and prediction of neurological outcome. J Matern Fetal Neonatal Med 2012 Mar;25(3):231-236.

53. Talic A, Kurjak A, Ahmed B, Stanojevic M, Predojevic M, Kadic AS, Di Renzo GC. The potential of 4D sonography in the assessment of fetal behavior in high-risk pregnancies. J Matern Fetal Neonatal Med 2011 Jul;24(7):948-954.

54. Miskovic B, Vasilj O, Stanojevic M, Ivanković D, Kerner M, Tikvica A. The comparison of fetal behavior in high risk and normal pregnancies assessed by four dimensional ultrasound. J Matern Fetal Neonatal Med 2010 Dec;23(12):1461-1467.

55. Andonotopo W, Kurjak A. The assessment of fetal behavior of growth restricted fetuses by $4 \mathrm{D}$ sonography. J Perinat Med 2006;34(6):471-478.

56. Talic A, Kurjak A, Stanojevic M, Honemeyer U, Badreldeen A, DiRenzo GC. The assessment of fetal brain function in fetuses with ventrikulomegaly: the role of the KANET test. J Matern Fetal Neonatal Med 2012 Aug;25(8):1267-1272.

57. Horimoto N, Koyanagi T, Maeda H, Satoh S, Takashima T, Minami T, Nakano H. Can brain impairment be detected by in utero behavioural patterns? Arch Dis Child 1993 Jul;69(1 Spec No):3-8. 
58. Prechtl HF, Einspieler C. Is neurological assessment of the fetus possible? Eur J Obstet Gynecol Reprod Biol 1997 Dec;75(1):81-84.

59. Nijhuis JG, Prechtl HF, Martin CB, Bots RS. Are there behavioral states in the human fetus? Early Hum Dev 1982 Apr;6(2):177-195.

60. Honemeyer U, Kurjak A. The use of KANET test to assess fetal CNS function. First 100 cases. 10th World Congress of Perinatal Medicine 8-11 November 2011. Uruguay. Poster presentation. p. 209

61. Vladareanu R, Lebit D, Constantinescu S. Ultrasound assessment of fetal neurobehaviour in high-risk pregnancies. Donald School J Ultrasound Obstet Gynecol 2012 Apr-Jun;6(2): 132-147.

62. Honemeyer U, Talic A, Therwat A, Paulose L, Patidar R. The clinical value of KANET in studying fetal neurobehavior in normal and at-risk pregnancies. J Perinat Med 2013 Mar;41(2):187-197.

63. Kurjak A, Talic A, Honemeyer U, Stanojevic M, Zalud I. Comparison between antenatal neurodevelopmental test and fetal Doppler in the assessment of fetal well being. J Perinat Med 2013 Jan;41(1):107-114.

64. Kurjak A, Predojevic M, Salihagic-Kadic A. Fetal brain function: lessons learned and future challenges of $4 \mathrm{D}$ sonography. Donald School J Ultrasound Obstet Gynecol 2010 Apr-Jun;2(5):85-92.

65. Greenwood C, Newman S, Impey L, Johnson A. Cerebral palsy and clinical negligence litigation: a cohort study. BJOG 2003 Jan;110(1):6-11.

66. Strijbis EM, Oudman I, van Essen P, MacLennan AH. Cerebral palsy and the application of the international criteria for acute intrapartum hypoxia. Obstet Gynecol 2006 Jun;107(6):1357-1365.

67. de Vries JI, Fong BF. Changes in fetal motility as a result of congenital disorders: an overview. Ultrasound Obstet Gynecol 2007 May;29(5):590-599.

68. de Vries JI, Fong BF. Normal fetal motility: an overview. Ultrasound Obstet Gynecol 2006 Jun;27(6):701-711.

69. Rosier-van Dunné FM, van Wezel-Meijler G, Bakker MP, de Groot L, Odendaal HJ, de Vries JI. General movements in the perinatal period and its relation to echogenicity changes in the brain. Early Hum Dev 2010 Feb;86(2):83-86.

70. Hata T, Kanenishi K, Akiyama M, Tanaka H, Kimura K. Realtime 3-D sonographic observation of fetal facial expression. J Obstet Gynaecol Res 2005 Aug;31(4):337-340.

71. Kozuma S, Baba K, Okai T, Taketani Y. Dynamic observation of the fetal face by three-dimensional ultrasound. Ultrasound Obstet Gynecol 1999 Apr;13(4):283-284.

72. Kurjak A, Azumendi G, Andonotopo W, Salihagic-Kadic A. Three- and four-dimensional ultrasonography for the structural and functional evaluation of the fetal face. Am J Obstet Gynecol 2007 Jan;196(1):16-28.

73. Predojević M, Talić A, Stanojević M, Kurjak A, Salihagić Kadić A. Assessment of motoric and hemodynamic parameters in growth restricted fetuses - case study. J Matern Fetal Neonatal Med 2014 Feb;27(3):247-251.

74. Athanasiadis AP, Mikos T, Tambakoudis GP, Theodoridis TD, Papastergiou M, Assimakopoulos E, Tarlatzis BC. Neurodevelopmental fetal assessment using KANET scoring system in low and high risk pregnancies. J Matern Fetal Neonatal Med 2013 Mar;26(4):363-368.
75. Stanojevic M, Antsaklis P, Salihadic-Kadic A, Predojevic M, Vladareanu R, Vladareanu S, Neto RM. Is Kurjak antenatal neurodevelopmental test ready for routine clinical application? Bucharest consensus statement. DSJUOG 2015 Jul-Sep;9(3):260-265.

76. Spencer-Smith MM, Spittle AJ, Doyle LW, Lee KJ, Lorefice L, Suetin A, Pascoe L, Anderson PJ. Long-term benefits of homebased preventive care for preterm infants: a randomized trial. Pediatrics 2012 Dec;130(6):1094-1101.

77. Neto RM, Kurjak A. Recent results of the clinical application of KANET test. DSJUOG 2015 Oct-Dec;9(20):420-425.

78. Hanaoka U, Hata T, Kananishi K, Mostafa AboEllail MA, Uematsu R, Konishi Y, Kusaka T, Noguchi J, Marumo G, Vasilj $\mathrm{O}$, et al. Does ethnicity have an effect on fetal behavior? A comparison of Asian and Caucasian populations. J Perinat Med 2016 Mar;44(2):217-221.

79. Neto RM. KANET in Brazil: first experience. Donald School J Ultrasound Obstet Gynecol 2015 Jan-Mar;9(1):1-5.

80. Schacher, S. Determination and differentiation in the development of the nervous system. In: Kandel ER, Schwartz JH, editors. Principles of neural science. 2nd ed. New York, Amsterdam, Oxford: Elsevier Science Publishing; 1985. p. $730-732$.

81. Kostovic I. Prenatal development of nucleus basalis complex and related fibre system in man: a histochemical study. Neuroscience 1986 Apr;17(4):1047-1077.

82. Kostovic, I. Zentralnervensystem. In: Hinrichsen KV, editor. Humanembryologie. Berlin: Springer-Verlag; 1990. p. 381-448.

83. Kuo AD. The relative roles of feedforward and feedback in the control of rhythmic movements. Motor Control 2002 Apr;6(2):129-145.

84. Ferrari F, Cioni G, Einspieler Ch, Roversi FM, Bos AF, Paolicelli PB, Ranzi A, Prechtl HFR. Cramped synchronized general movements in preterm infants as an early marker for cerebral palsy. Arch Pediatr Adolesc Med 2002 May;156(5): 460-467.

85. Latal-Hajnal B, Siebenthal K, Kovari H, Bucher HU, Largo RH. Postnatal growth in VLBW infants: significant association with neurodevelopmental outcome. J Pediatr 2003 Aug;143(2): 163-170.

86. Himmelmann K, Hagberg G, Wiklund LM, Eek MN, Uvebrant P. Dyskinetic cerebral palsy: a population-based study of children born between 1991 and 1998. Dev Med Child Neurol 2007 Apr;49(4):246-251.

87. Palmer FB. Strategies for the early diagnosis of cerebral palsy. J Pediatr 2004 Aug;145(2 Suppl):S8-S11.

88. Hadders-Algra M. Early diagnosis and early intervention in cerebral palsy. Front Neurol 2014 Sep;5:185.

89. Einspieler C, Marschik PB, Pansy J, Scheuchenegger A, Krieber M, Yang H, Kornacka MK, Rowinska E, Soloveichick M, Bos AF. The general movement optimality score: a detailed assessment of general movements during preterm and term age. Dev Med Child Neurol 2016 Apr;58(4):361-368.

90. Hadders-Algra M. General movements: a window for early identification of children at high risk for developmental disorders. J Pediatr 2004 Aug;145(2 Suppl):S12-S18.

91. Bennema AN, Schendelaar P, Seggers J, Haadsma ML, Heineman MJ, Hadders-Algra M. Predictive value of general movements' quality in low-risk infants for minor neurological dysfunction and behavioural problems at preschool age. Early Hum Dev 2016 Feb;94:19-24.

92. Kurjak A, Talic A, Stanojevic M, Honemeyer U, Serra B, Prats $\mathrm{P}$, Di Renzo GC. The study of fetal neurobehavior in twins in all 
three trimesters of pregnancy. J Matern Fetal Neonatal Med 2013 Aug;26(12):1186-1195.

93. Stanojevic M. Antenatal and postanatal assessment of neurobehavior: which one should be used? Donald School J Obstet Gynecol 2015 Jan-Mar;9(1):67-74.

94. Sekulić SR, Lukac DD, Naumović NM. The fetus cannot exercise like an astronaut: gravity loading is necessary for the physiological development during second half of pregnancy. Med Hypotheses 2005;64(2):221-228.
95. Assaiante C, Mallau S, Viel S, Jover M, Schmitz C. Development of postural control in healthy children: a functional approach. Neural Plast 2005;12(2-3):109-118, discussion 263-272.

96. Sellers JS. Relationship between antigravity control and postural control in young children. Phys Ther 1988 Apr;68(4):486-490.

97. Meigal AY. Synergistic action of gravity and temperature on the motor system within the lifespan: a "Baby Astronaut" hypothesis. Med Hypotheses 2013 Mar;80(3):275-283. 